\title{
A ground-motion prediction equation for Fennoscandian nuclear installations
}

\section{Fülöp, Ludovic}

2020-06

Fülöp , L , Jussila , V , Aapasuo , R M , Vuorinen , T A T \& Mäntyniemi , P B 2020 , ' A ground-motion prediction equation for Fennoscandian nuclear installations ', Bulletin of the Seismological Society of America, vol. 110 , no. 3 , pp. 1211-1230 . https://doi.org/10.1785/0120190230

http://hdl.handle.net/10138/329824

https://doi.org/10.1785/0120190230

unspecified

acceptedVersion

Downloaded from Helda, University of Helsinki institutional repository.

This is an electronic reprint of the original article.

This reprint may differ from the original in pagination and typographic detail.

Please cite the original version. 
A ground-motion prediction equation for Fennoscandian nuclear installations

Ludovic Fülöp*, Vilho Jussila, Riina Aapasuo, Tommi Vuorinen, Päivi Mäntyniemi

* Corresponding author

VTT Technical Research Center of Finland Ltd, P.O. Box 1000, FI-02044 Espoo, Finland

e-mail: ludovic.fulop@ vtt.fi, phone: +358 405934698

Key points:

1. We developed a ground-motion prediction equation for Fennoscandia, using the G16 model by Graizer (2016) as the backbone.

2. We show that the Fennoscandian spectra are compatible with the NGA-East (mostly eastern Canadian) spectra.

3. The new Fenno-G16 GMPE is applicable to probabilistic seismic hazard analysis on very hard rock. 


\section{Abstract}

We propose a ground-motion prediction equation (GMPE) for probabilistic seismic hazard analysis of nuclear installations in Finland. We collected and archived the acceleration recordings of 77 earthquakes from seismic stations on very hard rock (VHR, i.e. the shear-wave velocity in the upper $30 \mathrm{~m}$ of the geological profile $=2800 \mathrm{~m} / \mathrm{s}$ according to the definition used in the nuclear industry) in Finland and Sweden since 2006 and computed the corresponding response spectra important for engineering evaluation. We augmented the narrow magnitude range of the local data by a subset of VHR recordings of 33 earthquakes from the Next-Generation Attenuation for CENA (NGA-East) database, mainly from eastern Canada. We adapted the backbone curves of the G16 equation proposed by Graizer (2016) for Central and Eastern North America (CENA). After the calibration, we evaluated the accuracy of the median prediction and the random error. We conclude that the GMPE developed can be used for predicting ground motions in Fennoscandia. Due to compatibility with the original G16 backbone curve and comparisons with the NGA-East GMPEs, we estimate that the formulation proposed is valid on VHR over the range of $2 \leq$ moment magnitude $\leq 7.0$ and $0 \leq$ rupture distance $\leq 300 \mathrm{~km}$, the depth range over $1.5-37 \mathrm{~km}$, and frequencies between 1 and $100 \mathrm{~Hz}$. The median of the composite prediction of the GMPE proposed was reasonable. The standard deviation of the prediction error $(\sigma)$ was over the range of $0.73 \sim$ 0.86, in ln spectral acceleration units, for the relevant spectral frequencies. This is somewhat lower than the G16 $\sigma$, indicating lower aleatory variability. The new Fenno-G16 GMPE is applicable over a wider range of magnitudes than the two older GMPEs available in Finland and fits the data better, especially for peak ground acceleration and $25 \mathrm{~Hz}$. 


\section{Introduction}

Ground-motion prediction equations (GMPEs) are used to determine earthquake ground motions expected at the target site as functions of earthquake size, distance from the source, site soil conditions, and other factors. GMPEs are a key component in seismic hazard analyses, and a large number of these equations are available globally (see Douglas 2019). Due to the low seismicity rates in stable continental regions (SCRs), many significant earthquakes have not been recorded by high-quality instruments, and there is a lack of strong-motion data available for this tectonic regime (e.g. Goulet et al. 2014). Consequently, GMPEs in the SCRs are often based on numerical simulations of ground motions instead of recorded ground motions (e.g. Toro et al. 1997, Atkinson and Boore 2006, Edwards and Fäh 2013, Rietbrock et al. 2013). Other widely used techniques include the hybrid-empirical method (Campbell 2003, 2014) and the referenced empirical approach (Atkinson 2008).

The continuing growth of the global strong-motion database (e.g. Ancheta et al. 2014) and evolved peer-reviewed GMPEs (e.g. Abrahamson et al. 2014) have also accelerated attenuation modeling in SCRs. For example, European ground-motion observations have been compared with the empirical GMPEs developed. Using plate-boundary data (Cotton et al. 2008), GMPEs developed for larger magnitudes have been tested against small-magnitude data $(3.8 \leq$ moment magnitude $M_{w} \leq 4.5$; Beauval et al. 2012), and GMPEs developed for active tectonic environments have been tailored to moderate-seismicity regions (Bindi et al. 2017).

This investigation aims at developing a GMPE for Finland and its vicinity. Finland is situated in northern Europe within the SCR of the Fennoscandian Shield, where the surface area covers some of Earth's most ancient continental crust from Precambrian time. The heavily fractured uppermost $200 \mathrm{~m}$ of the crystalline bedrock exhibit shear-wave velocities $\left(\mathrm{V}_{\mathrm{s}}\right)$ from $2800 \mathrm{~m} / \mathrm{s}$ to $2950 \mathrm{~m} / \mathrm{s}$, 
which increase with depth (Grad and Luosto 1994). Earthquakes with local magnitude $\mathrm{M}_{\mathrm{L}}>3.5$ occur infrequently, but several earthquakes are felt annually without instruments, and areas of enhanced seismic activity have long been discerned (e.g. Gregersen et al. 1991). The historical seismicity record suggests that ground-motion attenuation in terms of macroseismic intensity is slow in the Fennoscandian Shield. For example, the $\mathrm{M}_{\mathrm{L}}=4.3( \pm 0.2)$ earthquake in central Finland on 16 November 1931 was clearly felt over radii of up to $150 \mathrm{~km}$ (Mäntyniemi 2004). Due to the low seismicity rate, the need for probabilistic seismic hazard analysis (PSHA) in the country is driven by mandatory site-specific analyses for critical installations, particularly nuclear power plants (NPPs). The current work was begun in the Evolving the Fennoscandian GMPE (EVOGY) project in the national program related to nuclear safety (Fülöp et al. 2019).

We adhere to the notion of similar tectonic regimes and augment the narrow magnitude range of available local data with earthquake recordings, mainly from eastern Canada. These data make it possible to extend the new GMPE over magnitudes relevant to NPP safety. We use the backbone curves of the G16 equation developed by Graizer (2016) for Central and Eastern North America (CENA). We chose the G16 equation, because it has evolved as part of the multidisciplinary project Next-Generation Attenuation for CENA (NGA-East) by the Pacific Earthquake Engineering Research Center, and it accords with the VHR definition used in the nuclear industry, i.e. (the average shear-wave velocity in the upper $30 \mathrm{~m}$ of the geological profile $\left(\mathrm{V}_{\mathrm{S} 30}\right)=2800$ $\mathrm{m} / \mathrm{s})$. The G16 model is not estimated against very many measurable parameters related to the source, path, or site. For example, $\mathrm{M}_{\mathrm{w}}$, the closest distance to the fault rupture plane $\left(\mathrm{R}_{\text {rup }}\right), \mathrm{V}_{\mathrm{S} 30}$, and anelastic attenuation factor $\mathrm{Q}_{0}$. We prefer the G16 model to the later formulation (Graizer 2017), because we focus on the closer distances that are of main concern for NPPs according to deaggregation studies. 
The G16 predicts the average horizontal component of peak ground acceleration (PGA) and the spectral accelerations (SAs), based on the NGA-East dataset (Goulet et al. 2014). A special feature of the G16 is that it separately predicts the PGA attenuation and a standard spectral shape (SAnorm). The $\mathrm{SA}_{\text {norm }}$ changes with magnitude and distance, whereas a general form of the acceleration spectra is assumed. Hence, the G16 is not entirely empirical; instead, it combines the empirical data with the assumed properties of ground-motion attenuation, based on known physical phenomena to create a semiempirical prediction. The NGA-East dataset alone is insufficient for a completely empirical prediction (Graizer 2016). In the following, we review datasets for the adjustment, investigate the G16 equation for VHR conditions, and formulate the adjustments needed to predict the PGA and spectra in Fennoscandia. After calibration of the adjusted GMPE, we evaluate the median prediction and error, using the calibration data, and compare the newly adjusted Fenno-G16 GMPE with those by Varpasuo et al. (2001) and Vuorinen et al. (2018), used in PSHA for nuclear installations in Finland. 


\section{Data used for adjustments of the G16 model}

The following datasets were considered in the EVOGY project (Fülöp et al. 2019) for adaptation of the G16 equation to Fennoscandian conditions:

(1) Fennoscandian earthquake recordings limited to low magnitudes $\left(\mathrm{M}_{\mathrm{L}} \leq 4.2\right)$; and

(2) an eastern Canadian subset of the NGA-East data (Goulet et al. 2014). The largest magnitude in the data is $M_{w}=6.76$, also used in the calibration of the G16 prediction.

As a first step, we assembled the recordings of local and regional earthquakes recorded at Finnish and Swedish seismic stations since 2006, when continuous waveform data became accessible. A total of 185 earthquakes between 2006 and 2018 were available over the magnitude range $1.5 \leq$ $M_{L} \leq 4.2$. The largest event, the Sveg earthquake of 15 September 2014 with $M_{L}=4.2$, was located in central Sweden, with only two recordings at stations in Finland, using $50-\mathrm{Hz}$ sampling at distances of $236 \mathrm{~km}$ and $271 \mathrm{~km}$, and additional 100-Hz recordings at $337 \mathrm{~km}$ and above. These recordings were removed from the data, because they were incompatible with the calibration and frequency ranges. The largest remaining earthquake, the Gulf of Bothnia earthquake of 19 March 2016 with $\mathrm{M}_{\mathrm{L}}=4.1$, is represented by 15 good-quality recordings within $300 \mathrm{~km}$ from the epicenter. For the final analysis, we accepted earthquakes with $M_{L} \geq 2$, because the smaller events showed few recordings and poor distance coverage. We selected the recordings with at least a 100Hz sampling rate and hypocentral distance $\mathrm{R}_{\mathrm{hyp}} \leq 300 \mathrm{~km}$, which resulted in 273 recordings of 77 earthquakes (Table 1). The corresponding range of depth is $1.5-36.9 \mathrm{~km}$ (Fig. 1).

The local magnitude scale of Helsinki, $\mathrm{M}_{\mathrm{L}}=\mathrm{M}_{\mathrm{L}(\mathrm{HEL})}$, is based on synthesized Wood-Anderson amplitudes of $\mathrm{Sg} / \mathrm{Lg}$ waves generated by local and regional earthquakes in Fennoscandia (Uski and Tuppurainen 1996). Seismic moments are not routinely produced for earthquakes in Finland, while the moment magnitude $\mathrm{M}_{\mathrm{w}(\mathrm{UPP})}$ of Uppsala University in Sweden is based on automated 
moment calculation. The Swedish $\mathrm{M}_{\mathrm{w}}$ relation can be used to extract seismic moments for earthquakes with available $\mathrm{M}_{\mathrm{w}(\mathrm{UPP})}$ and $\mathrm{M}_{\mathrm{L}(\mathrm{HEL})}$ determinations. The $\mathrm{M}_{\mathrm{w}(\mathrm{HEL})}$ moment magnitude scale of Helsinki was determined, using regression analysis and $\mathrm{M}_{\mathrm{L}}$ estimation to fit the moment vs. magnitude data piecewise to the lower and upper magnitude ranges. At the magnitude range available, the measurement uncertainty was larger than the difference between the converted $\mathrm{M}_{\mathrm{L}}$ and the $\mathrm{M}_{\mathrm{w}}$ (M. Uski, personal communication). Thus, we accept the approximations $\mathrm{M}_{\mathrm{L}} \sim \mathrm{M}_{\mathrm{w}}$. Each seismogram comprised $180 \mathrm{~s}$ of recording. As preprocessing, the linear component was removed by detrending, and 5\% Hann window tapering was applied. The trace was then filtered, using a $0.05-\mathrm{Hz}(20-\mathrm{s})$ high-pass filter. To remove the instrument response, the displacement response taken from the database was converted into the velocity and acceleration domains. The stability and correctness of the response removal were ensured by comparing the signal after the response removal with the preprocessed signal multiplied by a sensitivity constant in the velocity domain. If the absolute value of the correlation was 0.9 or higher, the displacement, velocity, and acceleration responses were removed from the filtered trace. To further enhance the stability, the maximum amplification of the response removal at a given frequency was limited by the water level (in $\mathrm{dB}$ ). If the correlation was below 0.9, the default value of 600 was adjusted, using four different steps: 100,10, 1, and 0 . If the response of the recording station is correct, the water level of 0 is effectively equivalent to multiplying the seismogram with the system's velocity sensitivity (Zhou 2014).

We calculated the geometric mean (GM) spectra and two rotation-independent spectra (RotD50, RotD100; Boore et al. 2006). Both the GM and RotD50 spectra are average spectra. For compatibility with the NGA-East data and the original G16, we used the RotD50 spectra. Finally, the Fennoscandian data were augmented with a subset of the NGA-East database, comprising 33 
earthquakes (Table 1) and their respective spectra. For a complete list of the spectra, see Table S1 available in the electronic supplement to this article. 
Adjusting the G16 prediction to Fennoscandia: peak ground acceleration 
The formulations of the G16 prediction for very-hard rock conditions are briefly outlined, following Graizer (2016). The adjustments of the PGA attenuation and a standard spectral shape ( $\left.\mathrm{SA}_{\text {norm}}\right)$ to Fennoscandia are presented separately. We used the same variable names and naming conventions as given in Graizer (2016). Some of the formulations were adapted from the Matlab code shared by Dr. Graizer, and additional clarifications were added from personal communication.

\section{Formulation of the G16 ground-motion prediction equation for peak ground acceleration}

The median PGA for ground with surface $\mathrm{V}_{\mathrm{S} 30}=640 \mathrm{~m} / \mathrm{s}$ in the $\mathrm{G} 16$ formulation reads as

$P G A_{G 16}=G_{1} \cdot G_{2} \cdot G_{3} \cdot C_{m e a n}$,

and, on the VHR conditions with $\mathrm{V}_{\mathrm{S} 30}=2800 \mathrm{~m} / \mathrm{s}$, it is given as

$P G A_{2800}=P G A_{G 16} \cdot G_{4}$

In Equations (1) and (2), the $G$ terms represent different filters as follows:

The term $G_{1}$ describes the magnitude-scaling filter and is defined as

$G_{1}=\left[c_{1} \arctan \left(M_{w}+c_{2}\right)+c_{3}\right] \cdot F$ 
with constant $F=2.232$. The term $G_{2}$ is the filter corresponding to the distance attenuation and is defined as

$G_{2}=\frac{1}{\sqrt{\left[\left(1-\frac{R_{\text {rup }}}{R_{\text {cor }}}\right)^{2}+4 D_{2}{ }^{2} \frac{R_{\text {rup }}}{R_{\text {cor }}}\right]}}$

with $R_{c o r}=c_{4} M_{w}+c_{5}$.

$G_{3}$ is the filter corresponding to anelastic attenuation defined as

$G_{3}=\exp \left(-\frac{c_{11}+c_{12} M_{w}}{Q_{0}} \cdot R_{\text {rup }}\right)$

$G_{4}$ is the site correction filter adjusting for the local shear-wave profile with the general form of

$G_{4}=\frac{1-0.5 \cdot \ln \left(\frac{V_{S 30}}{2800}\right)}{1-0.5 \cdot \ln \left(\frac{640}{2800}\right)}$.

For $\mathrm{V}_{\mathrm{S} 30}=2800 \mathrm{~m} / \mathrm{s}, G_{4}$ is a constant $(=0.57534)$ that reduces the $\mathrm{G} 16$ prediction of $\mathrm{PGA} 640 \mathrm{~m} / \mathrm{s}$ to

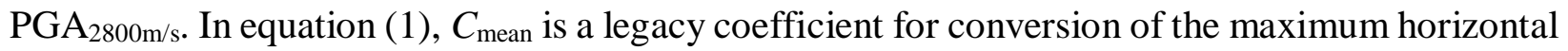
component to the average horizontal component $(=0.89758)$.

Including the error term in the log space gives

$\ln \left(P G A_{2800}\right)=\ln \left(P G A_{G 16}\right)+\ln \left(G_{4}\right)+\epsilon_{Y}$, 
where $\epsilon_{\mathrm{y}}$ is the random error term, modeled as a log distribution with a zero mean and standard deviation of the prediction error $(\sigma)$. The composite standard deviation of the G16 model PGA prediction is $\sigma=0.848$ in $\ln (\mathrm{PGA})$ units (Graizer 2016).

The constants calibrated for the G16 by Graizer (2016) are: $\mathrm{c}_{1}=0.4, \mathrm{c}_{2}=-6.25, \mathrm{c}_{3}=0.55, \mathrm{c}_{4}=$ 2.237, $\mathrm{c}_{5}=-7.542, \mathrm{c}_{11}=3.9, \mathrm{c}_{12}=-0.3445, \mathrm{~F}=2.232$, and $\mathrm{D}_{2}=0.7$. The value used for the regional quality factor $\left(\mathrm{Q}_{0}\right)$ for $1 \mathrm{~Hz}$ was $\mathrm{Q}_{0}=650$ (Erickson et al. 2004).

There are incompatibilities between the measurable parameters related to source, path, and site used in the G16 and those available in Fennoscandia. We accept that the $\mathrm{R}_{\text {hyp }}$ accords approximately with the $\mathrm{R}_{\text {rup, }} \mathrm{R}_{\text {hyp }} \sim \mathrm{R}_{\text {rup }}$, because small-magnitude earthquakes have a limited rupture area. We also accept the approximations $\mathrm{M}_{\mathrm{L}} \sim \mathrm{M}_{\mathrm{w}}$, since the estimated magnitude error of the Fennoscandian dataset ( \pm 0.2 units) exceeds the error introduced by the magnitude conversion. No value of $\mathrm{Q}_{0}$ for propagation of seismic waves from the source to site at $1 \mathrm{~Hz}, \mathrm{Q}_{0}$, is readily available for Fennoscandia; however, its influence is not strong in the near field.

\section{Formulation of the adjusted magnitude-scaling filter}

We attempted to adjust the PGA for lower magnitudes, using the Fennoscandian data while keeping the higher magnitude range unchanged and limiting the calibration to $\mathrm{R}_{\text {rup }} \leq 300 \mathrm{~km}$. We used different strategies to compare the data with the G16 formulation, keeping in mind that only the $\mathrm{M}_{\mathrm{L}}=4.1$ event recordings were in the calibration range of the $\mathrm{G} 16$.

The first issue with the G16 concerned the expression of $G_{1}$ (Eqs. 1-3). Together with $C_{\text {mean }}$ and

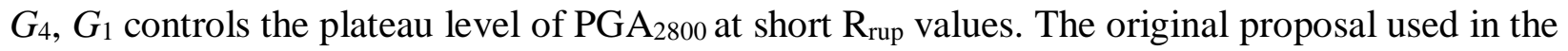
G16 saturated at high $M_{w}$ and decayed more slowly at low $M_{w}$. For $M_{w}=1.2$ and $R_{\text {rup }}=0 \mathrm{~km}$, the expression predicts a negative PGA. Since the shortest distance in the Fennoscandian dataset was

$\mathrm{R}_{\mathrm{hyp}}=19.3 \mathrm{~km}$, it was not possible to directly verify the prediction. From the NGA-East dataset, 
we added the three recordings of the $\mathrm{M}_{\mathrm{w}}=6.76$ Nahanni earthquake recorded at only $5-10 \mathrm{~km}$ on $\mathrm{V}_{\mathrm{S} 30}=1700 \mathrm{~m} / \mathrm{s}$. These datasets indicated that the $G_{1}$ scaling was at least reasonable for small magnitudes, and we used it without modification down to $\mathrm{M}_{\mathrm{w}}=2$.

\section{Formulation of the adjusted distance attenuation filter}

The $G_{2}$ factor controlling the extent of the PGA plateau was also examined with respect to the available data. The plateau decreases with decreasing magnitude according to the expression $R_{\text {cor }}=c_{4} M_{w}+c_{5}$, the 'corner distance' (Graizer 2016). There are no recordings to directly confirm $G_{2}$, because we did not observe a plateauing of the PGA at the distances recorded. For $\mathrm{M}_{\mathrm{w}}$ $\leq 3.37$, however, the $\mathrm{R}_{\text {cor }}$ becomes nonpositive, $R_{\text {cor }}=\left(c_{4} M_{w}+c_{5}\right) \leq 0$. We argue that the $\mathrm{R}_{\text {cor }}$ should be dependent on the depth of the earthquakes, and we did not expect it to decrease to zero with decreasing magnitudes.

Additionally, the $G_{2}$ formulation used by Graizer (2016) for distance attenuation assumes a constant attenuation slope equal to unity, once the distance increases beyond the plateau range. This assumption is reasonably accurate for large earthquakes, but it was not confirmed by measurements from small-magnitude quakes. We observed a variation in the attenuation slope from a value of about 2 at $\mathrm{M}_{\mathrm{w}}=2$, gradually decreasing to about 1 at $\mathrm{M}_{\mathrm{w}}=7$. To fit the $G_{2}$ filter to the data, they were divided in intervals of width $\mathrm{M}_{\mathrm{w}}=0.4$, starting from magnitude 2 . Each bin contained a sufficient number of data points, and data were distributed with $\mathrm{R}_{\text {rup }}$ to allow a stable determination of the slope factor $\left(\mathrm{S}_{1}\right)$ and $\mathrm{R}_{\text {cor }}$ of filter $G_{2}$. The factors of filter $G_{2}$ could be calibrated for nine bins. $S_{1}$ gradually decreases, and the $R_{\text {cor }}$ gradually increases with magnitude (Fig. 2).

A gradual decrease in the attenuation slope was imposed in the backbone of the hybrid-empirical model by Pezeshk et al. (2011). We adapted the $G_{2}$ formulation of the G16 to take into account a 
magnitude-dependent slope variation, as shown in Equation 8, and fitted the $\varepsilon_{1}$ and $\varepsilon_{2}$ factors to the data at magnitudes with at least 10 measurements spread over a distance of $100 \mathrm{~km}$. Thus,

$G_{2}=\frac{1}{\sqrt{\left[\left(1-\left(\frac{R_{\text {rup }}}{R_{\text {cor }}}\right)^{S_{l}}\right)^{2}+1.96 \cdot\left(\frac{R_{\text {rup }}}{R_{\text {cor }}}\right)^{S_{l}}\right]}}$

where

$S_{l}=\varepsilon_{1} \cdot M_{w}+\varepsilon_{2}$ is the magnitude-dependent slope factor.

Finally, we re-evaluated the $\mathrm{R}_{\text {cor }}$ values, based on the Fennoscandian data merged with the VHR recordings from the NGA-East data. We fitted $c_{4}$ and $c_{5}$ to better represent this dataset and introduced a minimum and maximum threshold for $\mathrm{R}_{\text {cor }}$ by limiting the expression $R_{c o r}=c_{4} M_{w}+$ $c_{5}$ in the range of $5.5 \mathrm{~km} \leq \mathrm{R}_{\text {cor }} \leq 12.5 \mathrm{~km}$. We calibrated $\mathrm{c}_{4}, \mathrm{c}_{5}, \mathrm{R}_{\text {cor_min, }}$ and $\mathrm{R}_{\text {cor_max }}$ for the best fit to the data. The parameters adapted correspond to $R_{\text {cor_max }}$ equivalent to $M_{w}=4.85$. Above this magnitude the parameter $R_{\text {cor }}$ assumes the constant value of $12.5 \mathrm{~km}$. There are 29 recordings in the dataset substantiating the threshold of $R_{\text {cor_max. }}$ We compared our prediction to the initial G16 in the range of $\mathrm{M}_{\mathrm{w}} 5-7$, concluding that the prediction proposed is slightly higher.

\section{Formulation of the adjusted anelastic filter}

The third element of the G16 attenuation is the anelastic filter $G_{3}$, controlled by $\mathrm{c}_{11}, \mathrm{c}_{12}$, and $\mathrm{Q}_{0}$. The use of frequency-independent anelastic attenuation, constant $\mathrm{Q}_{0}$, is itself a simplification discussed in detail by Graizer (2016, 2017). Havskov et al. (2016) also highlighted the sensitivity of coda $\mathrm{Q}$ to the analysis methodology and parameters. In the near-distance range $\mathrm{R}_{\text {rup }}<100 \mathrm{~km}$, however, the influence of $\mathrm{Q}_{0}$ was quite limited, so for an estimation of the fit we needed to examine 
longer distances than in the core calibration. First, we compared the prediction of the G16 with the original parameters, including $\mathrm{Q}_{0}=650$ in the recordings of the two Fennoscandian events with $\mathrm{M}_{\mathrm{L}}>4$, which are in the validity range of the G16. We separated the recordings at the local network in Ostrobothnia, Finland (OBF) at $250 \mathrm{~Hz}$ (Fig. 1) from those by the single seismic stations of the national network at $100 \mathrm{~Hz}$ (Fig. 3). The G16 prediction was lower for $\mathrm{Q}_{0}=650$, the mean being shifted by 0.4327 in ln units. An optimal $Q_{0}$ preserving all other parameters of the G16 would be $\mathrm{Q}_{0}=991.64$, with residual of $\sigma=0.394$ in ln units (Fig. 3). A higher $\mathrm{Q}_{0}$ would be in line with the values of 410-1100 reported by Zhao and Mousavi (2018), including Shi et al. (1996), for Eastern North America and eastern Canada, but they contrasted with the values of $\mathrm{Q}_{0} \leq 350$ given for northern Finland by Pavlenko and Kozlovskaya (2018). Most of the data within our primary interest range $\left(\mathrm{R}_{\text {hyp }} \leq 300 \mathrm{~km}\right)$ aligned similarly for the two values, but to optimize the distance dependence of the Fenno-G16 residual we used $\mathrm{Q}_{0}=991.64$ for the PGA prediction.

\section{General comments}

We conclude that the G16 PGA scaling for the $2800-\mathrm{m} / \mathrm{s}$ ground conditions $\left(G_{1} \cdot C_{\text {mean }} \cdot G_{4}\right)$ fits the available data reasonably well. The distance scaling $\left(G_{2}\right)$ needed modification for a better fit to accommodate magnitudes smaller than initially intended in the G16 GMPE. We ignored the different shear-wave velocities in the Fennoscandia $(2800 \mathrm{~m} / \mathrm{s})$ and NGA-East data $(2000 \mathrm{~m} / \mathrm{s}$, except for the Nahanni recordings at $1700 \mathrm{~m} / \mathrm{s}$; Goulet et al. 2014), leaving the $G_{4}$ factor constant ( $=0.5754)$ for all cases. Finally, $G_{3}$ would need further consideration under the Fennoscandian conditions. We used the CENA value of $\mathrm{Q}_{0}=650$ (Erickson et al. 2004) for a start. We optimized the $G_{2}$ parameters and threshold magnitude for prediction of the mean logarithm of PGA. The PGAs recorded were compared with the G16 prediction in Figure 4. In the lowest magnitude interval, the highest PGA of $0.014 g$ belongs to the $M=2.4$ earthquake of 27 September 2008 ( $d=$ 
$17.3 \mathrm{~km}$ ) recorded at an $\mathrm{R}_{\text {hyp }}$ of $19.3 \mathrm{~km}$, which is the shortest $\mathrm{R}_{\text {hyp }}$ in the Fennoscandian data. GMPE development focused on intermediate-magnitude earthquakes that did not rupture the ground surface, so we argue that these very short $R_{\text {rup }}$ ranges were not feasible. The residuals of the PGA prediction, Res $=\ln \left(\mathrm{PGA}_{\text {predict }} / \mathrm{PGA}_{\text {data }}\right)$, can be modeled as a log distribution with $\sigma=$ 0.7795 , centered on the median with a shift of only -0.04241 , both in $\ln$ units. The shift in the mean prediction was also very small (0.03816), which showed that the log model is a good approximation for the PGA residuals. The prediction is reasonable for all magnitudes and distances (Fig. 5). The mean error is close to zero. The scatter observed is the variability that could be reduced by adding an additional input variable to the GMPE formulation. 


\section{Adjusting the G16 prediction to Fennoscandia: spectra}

\section{Formulation of the G16 ground-motion prediction equation for spectra}

The prediction of the G16 for spectra is given as

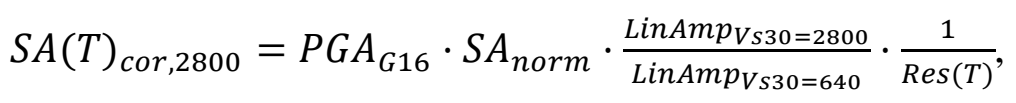

where $T$ is the spectral period $T=1 / f$, with frequency $f$, and $S A_{\text {norm }}$ is the normalized spectra. LinAmp $_{\mathrm{vs} 30=2800}$ is the site amplification to VHR conditions, equal to 1 . LinAmpvs $30=640$ is the site amplification to $\mathrm{V}_{\mathrm{S} 30}=640 \mathrm{~m} / \mathrm{s}$ relative to VHR conditions, where $640 \mathrm{~m} / \mathrm{s}$ is the mean shear-wave velocity of the G16 calibration dataset. $\operatorname{Res}(\mathrm{T})$ is a correction factor for residuals of the form $\operatorname{Res}(\mathrm{T})=\exp \left(\right.$ constant $_{1} \cdot \mathrm{R}_{\mathrm{rup}}-$ constant $\left._{2}\right)$. The values of the correction factors at 15 spectral periods can be found in Graizer (2016, Table A1). The SA(T) residuals.

The normalized spectral shape can be calculated as

$S A_{\text {norm }}=I \cdot \exp \left[-0.5\left(\frac{\ln (T)+\mu}{S}\right)^{2}\right]+\frac{1}{\sqrt{\left(1-\left(\frac{T}{T_{s p, 0}}\right)^{\xi}\right)^{2}+4 D_{s p}{ }^{2}\left(\frac{T}{T_{s p, 0}}\right)^{\xi}}}$

where intensity $(\mathrm{I})=1.4$ controls the amplification and $S=s_{1} \cdot R R-\left(s_{2} \cdot M M+s_{3}\right)$, the width of the spectra, in which $\mu$, the main factor controlling the peak amplification frequency $=m_{1}$. $R R+m_{2} \cdot M M+m_{3} . \mathrm{T}_{\mathrm{sp}, 0}$ is a secondary factor controlling the peak amplification frequency $=$

$t_{1} \cdot R R+t_{2} \cdot M M+t_{3}$, and $\xi=a_{1} \cdot M_{w}{ }^{2}+a_{2} \cdot M_{w}+a_{3}$ controls the slope of the spectra at low 
frequencies. The distance $R R$ is equal to $R_{r u p}$ for distances below $600 \mathrm{~km}$. The modified magnitude $(M M)$ is equal to the moment magnitude $M_{w}$ for $5.25<M_{w}<7.5$. For $M_{w} \leq 5.25$ it is equal to $M M=$ $5.25-0.4 \cdot\left(5.25-M_{w}\right)$.

The constants calibrated for $\mathrm{SA}_{\text {norm }}$ by Graizer (2016) are: $\mathrm{m}_{1}=-0.002, \mathrm{~m}_{2}=-0.12, \mathrm{~m}_{3}=3.0, \mathrm{t}_{1}=$ $0.0008, \mathrm{t}_{2}=0.16, \mathrm{t}_{3}=-0.4875, \mathrm{~s}_{1}=0.0, \mathrm{~s}_{2}=0.077, \mathrm{~s}_{3}=0.3251, \mathrm{a}_{1}=0.0347, \mathrm{a}_{2}=-0.5542, \mathrm{a}_{3}=3.694$, and $D_{s p}=0.75$. The parameter $s_{1}=0$ is a legacy parameter from previous versions of the GMPE. Finally,

$$
\operatorname{LinAmp}_{V s 30}=1+\frac{k_{V S 30}}{\sqrt{\left(1-\frac{f_{V S 30}}{f}\right)^{2}+1.96 \frac{f_{V S 30}}{f}}}
$$

with $k_{V s 30}=-0.5 \cdot \ln \left(\frac{V_{S 30}}{2800}\right)$ and $f_{V s 30}=\frac{V_{S 30}}{120}-1.6$. For the hard-rock conditions, $\operatorname{LinAmp}_{2800}=1$ and $f$ is the frequency considered in the spectra. Note that for a high frequency in the spectra $(f \rightarrow \infty)$, corresponding to the PGA, we have $1 / \mathrm{f}=\mathrm{T} \rightarrow 0, \mathrm{SA}_{\text {norm }} \rightarrow 1$, and LinAmp $_{2800} /$ LinAmp $_{640}=0.57534\left(=\mathrm{G}_{4}\right)$ from Equation 2. Hence, the SA prediction (Eq. 9) for VHR at high frequency is identical to the direct prediction of PGA on VHR (Eq. 2).

\section{Properties of the Fennoscandian spectra}

Errors accumulate when the PGA is multiplied with $\mathrm{SA}_{\text {norm }}$ in Equation 9. We tried to adapt the G16 spectral shape to the Fennoscandian data: the shape of the spectra is controlled by $\mathrm{SA}_{\text {norm}}$, the LinAmp factors, and the residual correction. It turned out that the residual correction significantly reduced the precision of predicting the shape of the Fennoscandia spectra. This was not surprising, considering that the residual correction was specifically introduced as the final adjustment in the 
initial G16 calibration (Graizer 2016). Trying to use the same residual correction with completely different data is bound to result in a poor prediction. One option could be to abandon the residual correction for $\mathrm{M}_{\mathrm{w}}<4$ over the range of the Fennoscandian data, but preserving it for $\mathrm{M}_{\mathrm{w}} \geq 4$. However, this would introduce a discontinuity at $\mathrm{M}_{\mathrm{w}}=4$.

Due to such problems, we recalibrated the spectral shape for the dataset, including the recordings of the Nahanni earthquake $\left(\mathrm{V}_{\mathrm{S} 30}=1700 \mathrm{~m} / \mathrm{s}\right)$, due to its large magnitude and recording at very short distances. To create the set, we analyzed the shape of the spectra of the Fennoscandian recordings. The highest sampling rate was $250 \mathrm{~Hz}$, while the bulk of the data was sampled at 100 Hz. Each spectrum was used only up to the value of the sampling frequency divided by 2.5 . Some spectra have anomalies at $0.1-1 \mathrm{~Hz}$, particularly small Fennoscandian events at large distances. We could not determine the reason for this anomaly, or eliminate it, but it was likely associated with poor signal-to-noise ratios.

One key shape parameter of the spectra is the amplification ( $\mathrm{SA}_{\max } / \mathrm{PGA}$ ) of about 3 (Figs. 6a,b), without a tendency to vary with magnitude or distance. The location of the amplification peak, the frequency at which the spectra peak, has high degree of randomness (Fig. 6c,d). Many recordings have $100-\mathrm{Hz}$ sampling, and the highest frequency we consider reliable is $40 \mathrm{~Hz}$, which also corresponds to the location of the peak (Figs. 6c,d). Therefore, we cannot establish whether the peak is natural or caused by the incompleteness of the signal. The peak frequency depends on magnitude (Fig. 6c), but not on distance (Fig. 6d). The third control parameter is the slope of the spectra at low frequencies in a log-log plane. The slope was calculated between $1 \mathrm{~Hz}$ and $2.5 \mathrm{~Hz}$, and it varies in the range of 1.5-3, with a mean at about 2 (Figs. 6e,f). 


\section{Adaptation of the G16 spectral shape}

MM is the modified magnitude introduced in the G16 GMPE, used in $\mu$ and $T_{s p, 0}$ such that both influence the position of the peak frequency. MM also influences the width of the spectra through parameter $S$. If we intend to adapt the G16 for magnitudes down to $\mathrm{M}_{\mathrm{w}}=2$, the effect of $\mathrm{MM}$ becomes very significant, practically controlling the prediction between $\mathrm{M}_{\mathrm{w}}=2$ and $\mathrm{M}_{\mathrm{w}}=4$.

We fitted the Fennoscandian data to the original G16 prediction, using MM extended to $\mathrm{M}_{\mathrm{w}}=2$. Due to the milder variation in MM compared with $\mathrm{M}_{\mathrm{w}}$, the spectral peak predicted dropped. This was not surprising, since at $\mathrm{M}_{\mathrm{w}}=2 \mathrm{MM}$ was almost doubled to 3.95 and controlled the position of the spectral peak. Therefore, we adjusted the G16 prediction to low magnitudes by eliminating $\mathrm{MM}$ for $\mathrm{M}_{\mathrm{w}} \leq 5.25$. The second threshold that influenced the position of the spectral peak concerned $T_{s p, 0}$. The two terms summed in Equation 10 define the shape of the spectra, and both $\mu$ and $T_{s p, 0}$ influenced the location of the spectral peak and the spectral amplification. Both $\mu$ and $T_{s p, 0}$, and in addition $S$, the factor controlling the width of the spectra, are dependent on the MM. With the formulation of $\mathrm{MM}$, we modified the spectra over the range of $\mathrm{M}_{\mathrm{w}}=4-5.24$. This change was not very significant, since it was demonstrated by the good fit of the NGA-East spectra over that magnitude range.

The $\mathrm{SA}_{\text {norm }}$ for Fennoscandia uses a modified MM definition for low magnitudes, as illustrated in Figure 7, and the lower threshold for $T_{s p, 0} \geq 2 \cdot \exp (-\mu)$. The adaptation proposal of MM resulted in narrower normal spectral shapes for small magnitudes. For magnitudes of 5.25, the shapes of the curves were identical to the original G16 formulation. The two functions contributing to the spectral shape in Equation 10 are illustrated in Figure 8 together with their sum. In Figure 8d, a slight difference can be observed for $\mathrm{M}_{\mathrm{w}}=5$. Figure $8 \mathrm{c}$ shows the smallest magnitude at which the 
original G16 would be valid. We changed the shape of the spectra for this magnitude, but we have data to confirm the validity of the change over this range.

For the parameter controlling the log-log plane slope of the spectra $(\xi)$, the G16 used the polynomial function $\xi=a_{1} \cdot M_{w}{ }^{2}+a_{2} \cdot M_{w}+a_{3}$, with coefficients calibrated up to $\mathrm{M}_{\mathrm{w}}=4$. We compared the equation at lower magnitudes with the slopes measured from the spectra and found no particular correlation of the slope with either $\mathrm{R}_{\mathrm{rup}}$ or $\mathrm{M}_{\mathrm{w}}$ (Fig. 6e,f). In contrast, the slopes are reasonably constant with a mean of approximately 2 , except for the Nahanni recordings with $M_{w}$ $=6.76$. For our data, a reasonable approximation was achieved by imposing a constant value of $\xi$ $=2.05$ for the entire data range.

The last adaptation was the location of the spectral peak and amplification. The modifications implemented so far resulted in a slow shift of the spectral peak towards higher frequencies as the magnitude decreased (Fig. 8). However, the comparisons showed that the peaks occurred at even higher frequencies, even at $40 \mathrm{~Hz}$, which is the limit of the validity of the spectra (Fig. $6 \mathrm{c}, \mathrm{d})$. The position of the spectral peak was also not strongly correlated with magnitude or distance, and the spectra were characterized by the extended plateau region. Due to this plateau, a less precise estimate of the location of the peak did not introduce a significant error in the prediction.

In the G16 formulation, the position of the spectral peak is primarily controlled by the factor $\mu=$ $m_{1} \cdot R R+m_{2} \cdot M M+m_{3}$. Utilizing the new definition of the MM (Fig. 7), we plotted the position of the spectral peak approximated as $1 / \exp (-\mu)$ for subsets of the data at $\sim \mathrm{M}_{\mathrm{w}}=2.1,3$, and 4.1 in Figure 9. With the original parameters of the G16, the location of the spectral peak was underestimated for smaller magnitudes and even for $\mathrm{M}_{\mathrm{w}}=4$, within the application range of the 
G16. We predicted the peak location, using $m_{2}=-0.1584, m_{3}=3.5756$, and the peak amplitude with $\mathrm{I}=1.81861$. The change in the peak location with distance $\left(m_{1}\right)$ was not altered. We optimized these parameters by simultaneously fitting the median prediction for frequencies between $1 \mathrm{~Hz}$ and $40 \mathrm{~Hz}$. As a result, the peak frequency was higher and the spectra narrower. The spectral amplification was also slightly increased compared with the G16 spectra.

We observed that, for this dataset, the prediction of the spectral shape was poorer if the LinAmp and residual corrections were applied in Equation 9. The spectra from the Fennoscandian dataset and the NGA-East subset with VHR recordings are very similar (Fig. 6). SA $\mathrm{max}_{\mathrm{ma}} / \mathrm{PGA}$ is of the order of 3, having only slight variation in magnitude and distance. The log-log plane slope was approximately 2. The main difference is in the location of the peak SAs, where the Fennoscandian data showed systematically higher frequencies for the peak than did the NGA-East subset. We formulated the normal spectral shape, using the combined data. The normal spectral shape can be used together with the adapted PGA prediction. 


\section{Results and Discussion}

Table 2 summarizes the adaptations proposed for the G16 GMPE, both for the PGA and SA. Table 3 shows the median values of the pseudospectral acceleration (PSA) residuals (Res = $\mathrm{PSA}_{\text {predict}} / \mathrm{PSA}_{\text {data }}$ ) for the $\mathrm{SA}_{\text {norm }}$ values and the $\sigma$ of the normal distributions fitted to $\ln$ for each frequency. Adaptation of the G16 follows the spectra over the range $0.1-40 \mathrm{~Hz}$. At $1 \mathrm{~Hz}$ and $2 \mathrm{~Hz}$, the residual value is $\sim 0.8$ and the values decrease toward higher frequencies. The larger residuals below $1 \mathrm{~Hz}$ reflect the presence of the anomalous peaks in the Fennoscandian spectra; the higher randomness below $1 \mathrm{~Hz}$ and the rather poor prediction of the median are expected.

Table 4 gives the cumulated errors of the Fenno-G16 prediction. The randomness of the normal spectral shape represented by $\sigma$ is low, especially over the frequency range of 1-40 Hz. This low degree of randomness confirms the validity of separating the normal shape prediction from the PGA prediction. The residuals of the Fenno-G16 model for SA prediction are reasonably centered with magnitudes and rupture distances for mid- $(15 \mathrm{~Hz})$ and low $(1 \mathrm{~Hz})$ frequencies (Fig. 10), similar to PGA (Fig. 5). The $\sigma$ of the proposed Fenno-G16 model is shown for different magnitude

ranges in Table 5. The highest randomness can be observed in the $\mathrm{M}_{\mathrm{w}} 3.5-5$ interval. We attribute this to the magnitude range of Fennoscandia being very mixed with Fennoscandian and NGA-East data.

Separating the intra- and interevent variability is very demanding, due to low seismicity and seismic networks that are not dense enough to have multiple recordings of the same smallmagnitude earthquake or a high number of recordings at each station. The partitioning of intraand interevent variability varies significantly (e.g. Atkinson 2006). We analyzed the residuals of the Fenno-G16 prediction at the three stations with at least 20 recordings. The mean predictions are well centered, with $\mathrm{R}_{\text {rup }}$ at the three stations. The $\sigma$ values can be found in Table 6 . The 
proportion of the single-station $\sigma$ seems to be of the order of $70-80 \%$ of the total $\sigma$. The homogeneity of site conditions in Fennoscandia - hard rock - probably reduces the site-effect. Due to the lack of extensive data on which to base the comparison, however, we recommend that only the total $\sigma$ of the Fenno-G16 GMPE should be used at this point. Moreover, the Fenno-G16 inherits the complexity of the G16 prediction, and the procedure for assessing the uncertainty of median prediction as outlined by Al Atik and Youngs (2014) is difficult to carry out analytically. Figure 11 exemplifies the differences between the normal spectral shapes of the selected data and the predicted spectra, using the closest recordings from Fennoscandia and the NGA-East subset for several magnitudes. Deaggregations have shown that near-field earthquakes contribute to the seismic hazard related to NPPs in Finland. The agreement is reasonable for magnitudes $\mathrm{M}_{\mathrm{w}} 4.1$ and 5.85 in particular (Figs. 11b,e), but the closest Fennoscandian recording at $19 \mathrm{~km}\left(\mathrm{M}_{\mathrm{w}} 2.4\right.$; Fig. 11a) deviates from the prediction. The closest recording at $5.3 \mathrm{~km}$ of the Nahanni earthquake also clearly deviates from the prediction (Fig. 11f). These are individual, rare recordings at close distances and subject to variability. At close distances, the strong-motion measurements can be highly varied (e.g. Shakal et al. 2006).

Figure 12 compares the attenuation features of the GMPE developed in this investigation (FennoG16) with those of Varpasuo et al. (2001; hereafter referred to as VNS2001) and Vuorinen et al. (2018; T-97) used in PSHA in Finland. Both equations were developed for VHR sites. The VNS2001 GMPE was based on the recordings of the Saguenay 1988 and Newcastle 1989 earthquakes and the separation of the respective longitudinal and transversal components. Its formulation combined the models of McGuire (1976) and Dahle et al. (1990). The T-97 GMPE followed the backbone of the hybrid-empirical model by Pezeshk et al. (2011). 
Plots are shown for PGA and SA at frequencies $5 \mathrm{~Hz}$ and $25 \mathrm{~Hz}$ for the largest Fennoscandian earthquake, with $M_{L}=4.1(d=23.5 \mathrm{~km})$ and the Saguenay earthquake with $\mathrm{M}_{\mathrm{w}}=5.8(\mathrm{~d}=29 \mathrm{~km})$. These frequencies correspond approximately to the building response and equipment qualification in NPPs, respectively. Each GMPE has its characteristic shape. The VNS2001 curves displayed rather rapid attenuation after the $\mathrm{R}_{\text {hyp }}$ of approximately $30 \mathrm{~km}$. For the PGA and SA $5 \mathrm{~Hz}$, the attenuation rate diminished at distances above $80 \mathrm{~km}$. The T-97 curves resembled the base model: Pezeshk et al. (2011) modeled the critical reflections arriving at $70 \mathrm{~km}$ and $140 \mathrm{~km}$, which explains the flat part of the attenuation curves between these distances. The predicted attenuation decreased quite rapidly between $5 \mathrm{~km}$ and $100 \mathrm{~km}$. In the case of $\mathrm{M}_{\mathrm{w}}=4.1$, the Fenno-G16 curves were between those of the other two models in all comparisons (Fig. 12a-c) and fit the available data well. The T-97 GMPE is not applicable to magnitudes above 5, so the original Pezeshk et al. (2011) GMPE was used in the comparisons (Fig. 12d-f). The Fenno-G16 model fit most of the observations quite well, especially for PGA and $25 \mathrm{~Hz}$ and is applicable over a wider range of magnitudes than the two older GMPEs. We recommend that the older GMPEs should not be used in future calculations of PSHA.

Comparison of the ordinal variable of macroseismic intensity with the instrumental PGA by definition leads to large degrees of scatter; however, the disparate quantities attenuated in parallel as a function of distance and respective comparisons are allowed. The macroseismic reports available showed that the $\mathrm{M}_{\mathrm{L}}=4.1$ earthquake of 19 March $2016(\mathrm{~d}=23.5 \mathrm{~km})$ was largely observed (at least $\mathrm{I}=4$ on the European Macroseismic Scale of 1998) in localities close to the OBF seismic network (Fig. 1), where the largest recorded PGA value was $0.0029 g$ at $R_{\text {epi }}=91 \mathrm{~km}$ and the smallest was $0.00095 \mathrm{~g}$ at $122 \mathrm{~km}$. Seismic station TOF recorded a PGA of $0.00136 \mathrm{~g}$ at $R_{\text {epi }}=140 \mathrm{~km}$. Multiple macroseismic observations from the two lowest floors of buildings in 
Finland were also received from distances up to $170 \mathrm{~km}$. Macroseismic reports of preinstrumental earthquakes in the same region also support the notion that the radii of perceptibility of $M>4$ earthquakes are not short.

The strict calibration range for the Fenno-G16 is from $M_{w}=2$ to 6.76 . For $M_{w}=6.76$, however, only the three recordings of the 23 December 1985 Nahanni earthquake constrained the prediction at distances $<10 \mathrm{~km}$. The ground-motion prediction was constrained for such a large magnitude in the near-field, but the attenuation was not. No data are available between $\mathrm{M}_{\mathrm{w}}=6.76$ and $\mathrm{M}_{\mathrm{w}}=$ 5.85 for the 25 November 1988 Saguenay earthquake. Hence, randomness in the upper magnitude range was expected to be lower than for multiple $\sim \mathrm{M}_{\mathrm{w}}=5.5-6$ events. The dataset covers multievent randomness at $\mathrm{M}_{\mathrm{w}}=5$ and below, where the GMPE developed relies on data, while between $M_{w}=5$ and $M_{w}=7$ it relies partly on data but also on the similarity of the prediction with the G16. Originally the Pezeshk et al. (2011) and Electric Power Research Institute EPRI (2013) GMPEs were used as the main constraints, especially for large magnitudes, by Graizer (2015). Later, simulations were provided in the NGA-East project with a recommendation for using the respective scaling ratios for magnitudes 5 and above. Stress-drop ratios have provided additional constraints (V. Graizer, personal communication). Comparisons in the larger range of magnitudes is presented in Figure 13 with the NGA-East GMPEs. The comparisons confirmed the satisfactory behavior of the Fenno-G16, with spectral amplification peak in the higher range of the individual NGA-East predictions. The match of Fenno-G16 with the NGA-East GMPE mean prediction at $\mathrm{M}_{\mathrm{w}} 4$ (Figure 13ab) offers the opportunity of coupled use in PSHA studies in VHR, where a prediction for magnitudes below $\mathrm{M}_{\mathrm{w}} 4$ is required.

We conclude that the Fenno-G16 GMPE developed can be used for predicting ground motions in Fennoscandia. The strict calibration range is $2 \leq \mathrm{M}_{\mathrm{w}} \leq 6.76$ and $0<\mathrm{R}_{\text {rup }} \leq 300 \mathrm{~km}$. Due to 
compatibility with the original G16 backbone curve, we estimate that the formulation proposed is valid on VHR over the range of $2 \leq M_{w} \leq 7.0$ and $0 \leq R_{\text {rup }} \leq 300 \mathrm{~km}$. The uncertainties associated with PSHA are inevitably large in the low-seismicity target region. The ground-motion logic tree typically has a major influence on the uncertainty modeled in PSHAs (e.g. Toro 2006). The standard approach is to populate the logic tree by several GMPEs to capture the epistemic uncertainty in the median ground-motion prediction and the associated aleatory variability (e.g. Bommer et al. 2005). Delavaud et al. (2012) provided an example of building a ground-motion logic tree for Europe. They included six GMPEs for the SCRs. Douglas (2018) discussed geographically varying uncertainty in regional and continental-scale PSHA models and pointed out discrepancies in the uncertainties between them and site-specific analyses. He presented a methodology in which the logic tree weights can be revised as more local data accumulate.

The new Fenno-G16 GMPE can be included in the logic tree as one branch among alternative GMPEs. Currently, the GMPEs available for SCRs often rely on CENA data. This investigation concludes a certain compatibility between Fennoscandian earthquake spectra and eastern Canadian hard-rock spectra. This is important because it will create confidence in future use of the NGAEast GMPE in PSHA in Finland. 


\section{Conclusions}

We propose a GMPE for Fennoscandia, Fenno-G16, based on an adaptation of the G16 GMPE by Graizer (2016). The proposal follows the logic of the G16 by separating the predictions of the PGA and the $\mathrm{SA}_{\text {norm. }}$. The cumulated error of the prediction is reasonable (Table 4). We collected and processed Fennoscandian earthquake recordings and supplemented them with mainly the eastern Canadian subset of the NGA-East database, recorded on rock with $V_{\mathrm{S} 30}=2000 \mathrm{~m} / \mathrm{s}$.

We show that the Fennoscandian spectra are compatible with the NGA-East (mostly eastern Canadian SCR) spectra (Fig. 6). This was already argued earlier, when previous GMPE proposals for Finland extensively used such data (Varpasuo et al. 2001). However, proof with a large comparative dataset has been worked out for the first time. We also show where the two datasets differ the most: in the position of the spectral peak. The Fennoscandian spectra peak at higher frequencies than the eastern Canadian spectra, even in the range of overlapping magnitudes (Fig. $6 c, d)$. This observation supports the extension of the design spectra for NPPs in Finland toward higher frequencies.

A reasonable prediction can be achieved for the $\mathrm{SA}_{\text {norm, }}$ VHR sites, and the distance range of interest in PSHAs for nuclear installations in Finland. This observation eliminates the need to predict each SA frequency independently, as done previously, bypassing some of the difficulties we had with Fennoscandian spectra at low frequencies. 


\section{Data and Resources}

The NGA-East data (Goulet et al. 2014) related to the Next-Generation Attenuation for Central and Eastern North America project by the Pacific Earthquake Engineering Research Center were downloaded from https://peer.berkeley.edu/research/nga-east. The data from the RotD50 5\% damping spectra in the 2018.11.18 version Public Flatfile were used. The Fennoscandian data used in this investigation were collected within the SAFIR EVOGY project and are available upon request. The electronic supplement to this article includes a table of spectra used in the calibration of the new Fenno-G16 GMPE. 


\section{Acknowledgements}

The authors acknowledge the financial support of the Finnish Research Program on Nuclear Power Plant Safety (SAFIR2018) and the energy utility Fennovoima Oy through the EVOGY project. Preliminary results are included in the Final Report of the SAFIR2018 program (Fülöp et al. 2019). We are also thankful for the support of the Radiation and Nuclear Safety Authority in Finland (STUK) in developing this work. We express our gratitude to Dr. Vladimir Graizer of the United States Nuclear Regulatory Commission for his support regarding the G16 GMPE. We thank Janika Tang for comments on a previous version of the manuscript and Kati Oinonen for plotting Figure

1. Thanks to James Thompson at the Language Center of the University of Helsinki for providing professional English language assistance during the preparation of this article. We thank John Douglas and two anonymous reviewers for their thorough remarks and suggestions that helped us to improve this work significantly. 


\section{References}

Abrahamson, N. A., W. J. Silva, and R. Kamai (2014). Summary of the ASK14 ground motion relation for active crustal regions, Earthq. Spectra 30 1025-1055.

Al Atik, L., and R. R. Youngs (2014). Epistemic uncertainty for NGA-West2 models, Earthq. Spectra 30 1301-1318.

Ancheta, T. D., R. B. Darragh, J. P. Stewart, E. Seyhan, W. J. Silva, B. S.-J. Chiou, K. E. Woddell, R. W. Graves, A. R. Kottke, D. M. Boore, T. Kishida, and J. L. Donahue (2014). NGA-West2 database, Earthq. Spectra 30 989-1005.

Atkinson, G. M. (2006). Single-station sigma, Bull. Seism. Soc. Am. 96 446-455. doi:10.1785/0120050137

Atkinson, G. M. (2008). Ground-motion prediction equation for Eastern North America from a referenced empirical approach: Implications for epistemic uncertainty, Bull. Seism. Soc. Am. $\mathbf{9 8}$ 1304-1318. doi:10.1785/0120070199

Atkinson, G. M., and D. M. Boore (2006). Earthquake ground-motion prediction equations for Eastern North America, Bull. Seism. Soc. Am. 96 2181-2205. https://doi.org/10.1785/0120050245 (erratum 97(3), 1032) 
Beauval, C., H. Tasan, A. Laurendeau , E. Delavaud, F. Cotton, P. Guéguen, and N. Kuehn (2012). On the testing of ground-motion prediction equations against small-magnitude data, Bull. Seism. Soc. Am. 102 1994-2007. doi:10.1785/0120110271

Bindi, D., F. Cotton, S. R. Kotha, C. Bosse, D. Stromeyer, and G. Grünthal (2017). Applicationdriven ground motion prediction equation for seismic hazard assessments in non-cratonic moderate-seismicity areas, J. Seismol. 21 1201-1218. doi:10.1007/s10950-017-9661-5

Bommer, J. J., F. Scherbaum, H. Bungum, F. Cotton, F. Sabetta, and N. A. Abrahamson (2005). On the use of logic trees for ground-motion prediction equations in seismic-hazard analysis, Bull. Seism. Soc. Am. 95 377-389. doi:10.1785/0120040073

Boore, D. M., J. Watson-Lamprey, and N. A. Abrahamson (2006). Orientation-independent measures of ground motion, Bull. Seism. Soc. Am. 96 1502-1511. doi:10.1785/0120050209

Campbell, K. W. (2003). Prediction of strong ground motion using the hybrid empirical method and its use in the development of ground-motion (attenuation) relations in Eastern North America, Bull. Seism. Soc. Am. 93 1012-1033.

Campbell, K. W. (2014). An evaluation of Eastern North American ground-motion models developed using the hybrid empirical method, Bull. Seism. Soc. Am. 104 347-359. doi: $\underline{10.1785 / 0120120256}$ 
Cotton F, G. Pousse, F. Bonilla, and F. Scherbaum (2008). On the discrepancy of recent European ground-motion observations and predictions from empirical models: Analysis of KiK-net accelerometric data and point-sources stochastic simulations, Bull. Seism. Soc. Am. 98 2244-2261. doi: $10.1785 / 0120060084$

Dahle, A., H. Bungum, and L. B. Kvamme (1990). Attenuation models inferred from intraplate earthquake recordings, Earthq. Eng. Struct. Dyn. 19 1125-1141.

Delavaud, E, F. Cotton, S. Akkar, F. Scherbaum, L. Danciu, C. Beauval, S. Drouet, J. Douglas, R. Basili, M. A. Sandikkaya, M. Segou, E. Faccioli, and N. Theodoulidis (2012). Toward a groundmotion logic tree for probabilistic seismic hazard assessment in Europe, J. Seismol. 16 451-473. doi:10.1007/s10950-012-9281-z

Douglas, J. (2018). Capturing geographically-varying uncertainty in earthquake ground motion models or what we think we know may change, in Recent Advances in Earthquake Engineering in Europe. ECEE 2018. K. Pitilakis (Editor), Geotechnical, Geological and Earthquake Engineering 46, Springer, Cham, 153-181. doi:10.1007/978-3-319-75741-4_6

Douglas, J. (2019). Ground motion prediction equations 1964-2019. http://www.gmpe.org.uk/ gmpereport2014.pdf_Accessed 7 March 2019

Edwards, B., and D. Fäh (2013). A stochastic ground-motion model for Switzerland, Bull. Seism. Soc. Am. 103 78-98. doi:10.1785/0120110331 
EPRI (2013). EPRI 2004-2006 Ground-motion model (GMM) review project 3002000717, Final Report, June 2013, Electric Power Research Institute, Palo Alto, California.

Erickson, D., D. E. McNamara, and H. M. Benz (2004). Frequency-dependent $L_{g} Q$ within the continental United States, Bull. Seism. Soc. Am. 94 1630-1643.

Fülöp, L., V. Jussila, R. Aapasuo, T. Vuorinen, and P. Mäntyniemi (2019). Evolving the Fennoscandian GMPEs (EVOGY), in SAFIR2018 - The Finnish Research Programme on Nuclear Power Plant Safety 2015-2018: Final report Jari Hämäläinen, Vesa Suolanen (Editors), VTT Technology No. 349, VTT Technical Research Centre of Finland, 422-433. doi: 10.32040/2242$\underline{122 X .2019 . T 349}$

Goulet, C. A., T. Kishida, T. D. Ancheta, C. H. Cramer, R. B. Darragh, W. J. Silva, Y. M. A. Hashash, J. Harmon, J. P. Stewart, K. E. Wooddell, and R. R. Young (2014). PEER NGA-East database, PEER Report 2014/17, Pacific Earthquake Engineering Research Center, Headquarters at the University of California, Berkeley.

Grad, M., and U. Luosto (1994). Seismic velocities and $Q$-factors in the uppermost crust beneath the SVEKA profile in Finland, Tectonophysics 230 1-18. 
Graizer, V. (2015). Ground-motion prediction equations for the Central and Eastern United States, in NGA-East: Median ground-motion models for the Central and Eastern North America Region, Pacific Earthquake Engineering Research Center (PEER), Report No. 2015/4, 213-249.

Graizer, V. (2016). Ground-motion prediction equations for Central and Eastern North America, Bull. Seism. Soc. Am. 106 1600-1612. doi:10.1785/0120150374

Graizer, V. (2017). Alternative (G-16v2) ground-motion prediction equations for Central and Eastern North America, Bull. Seism. Soc. Am. 107 869-886. doi:10.1785/0120160212

Gregersen, S., H. Korhonen, and E. S. Husebye (1991). Fennoscandian dynamics: Present-day earthquake activity, Tectonophysics 189 333-344.

Havskov, J., M. B. Sørensen, D. Vales, M. Özyazıcıŏglu, G. Sánchez, and B. Li (2016). Coda $Q$ in different tectonic areas, influence of processing parameters, Bull. Seism. Soc. Am. 106 956-970. doi: $10.1785 / 012150359$

Mäntyniemi, P. (2004). Pre-instrumental earthquakes in a low-seismicity region: A reinvestigation of the macroseismic data for the 16 November 1931 events in central Finland using statistical analysis, J. Seismol. 8 71-90.

McGuire, R. K. (1976). Fortran computer program for seismic risk analysis, USGS Open-File Report 4-76. 
Pavlenko, O., and E. Kozlovskaya (2018). Characteristics of radiation and propagation of seismic waves in Northern Finland, estimated based on records of local earthquakes, Pure Appl. Geophys. 175 4197-4223. doi:10.1007/s00024-018-1919-5

Pezeshk, S., A. Zandieh, and B. Tavakoli (2011). Hybrid empirical ground-motion prediction equations for Eastern North America using NGA models and updated seismological parameters, Bull. Seism. Soc. Am. 101 1859-1870. doi:/10.1785/0120100144

Rietbrock, A., F. Strasser, and B. Edwards (2013). A stochastic earthquake ground-motion prediction model for the United Kingdom, Bull. Seism. Soc. Am. 103 57-77. doi: $10.1785 / 0120110231$

Shakal, A., H. Haddadi, V. Graizer, K. Lin, and M. Huang (2006). Some key features of the strongmotion data from the M 6.0 Parkfield, California, earthquake of 28 September 2004, Bull. Seism. Soc. Am. 96(4B) S90-S118. doi: 10.1785/20050817

Shi, J., W. Kim, and P. Richards (1996). Variability of crustal attenuation in the Northeastern United States from Lg waves, J. Geophys. Res. 101 25,231-25,242.

Toro, G. R. (2006). The effects of ground-motion uncertainty on seismic hazard results: examples and approximate results, in Annual meeting of the Seismological Society of America. doi:10.13140/RG.2.1.1322.2007 
Toro, G. R., N. A. Abrahamson, and J. F. Schneider (1997). Model of strong ground motions from earthquakes in Central and Eastern North America: Best estimates and uncertainties, Seism. Res. Lett. 68 41-57. doi:10.1785/gssrl.68.1.41

Uski, M., and A. Tuppurainen (1996). A new local magnitude scale for the Finnish seismic network, Tectonophysics 261 23-37.

Varpasuo, P., J. Saari, and Y. Nikkari (2001). Seismic Hazard and Ground Motion for Leningrad NPP site, in Transactions of the $16^{\text {th }}$ International Conference on Structural Mechanics in Reactor Technology (SMiRT16), August 12-17, 2001, Washington DC, USA.

Vuorinen, T., T. Tiira, M. Uski, and B. Lund (2018). Updated Fennoscandian GMPE, Report T97, Institute of Seismology, University of Helsinki.

Zhao, L.-F., and S. M. Mousavi (2018). Lateral variation of crustal Lg attenuation in Eastern North America. Scientific Reports 8, No. 7285. doi:10.1038/ s41598-018-25649-5

Zhou, H.-W. (2014). Practical seismic data analysis, Cambridge University Press, Cambridge, New York. 
VTT Technical Research Center of Finland Ltd, P.O. Box 1000, FI-02044 Espoo, Finland (L.F., V.J.)

Institute of Seismology, University of Helsinki, P.O. Box 68, FI-00014 Helsinki, Finland (R.A., T.V., P.M.) 
Table 1. Combination of Fennoscandian and Next-Generation Attenuation for CENA (NGA-East) subset (mainly eastern Canadian) data used in the analysis.

\begin{tabular}{|c|c|c|c|c|c|}
\hline $\begin{array}{l}\text { Magnitude } \\
\text { interval }\end{array}$ & $\begin{array}{c}\text { No. of } \\
\text { Fennoscandian } \\
\text { events }\end{array}$ & $\begin{array}{l}\text { No. of NGA- } \\
\text { East } \\
\text { events }\end{array}$ & $\begin{array}{c}\text { Depth } \\
\text { ranges }(\mathrm{km})\end{array}$ & $\begin{array}{c}\text { No. of } \\
\text { Fennoscandian } \\
\text { recordings/spectra }\end{array}$ & $\begin{array}{l}\text { No. of NGA- } \\
\text { East spectra }\end{array}$ \\
\hline \multirow[t]{3}{*}{$2-2.5$} & \multirow[t]{3}{*}{50} & \multirow[t]{3}{*}{1} & $1.9-5$ & 17 & - \\
\hline & & & $5.1-10$ & 64 & - \\
\hline & & & $10.1-36.9$ & 61 & 5 \\
\hline \multirow[t]{3}{*}{$2.51-3$} & \multirow[t]{3}{*}{13} & \multirow[t]{3}{*}{7} & $1.5-5$ & 22 & 6 \\
\hline & & & $5.1-10$ & 9 & - \\
\hline & & & $10.1-30$ & 27 & 28 \\
\hline \multirow[t]{2}{*}{$3.01-3.5$} & \multirow[t]{2}{*}{7} & \multirow[t]{2}{*}{6} & $7.5-10$ & 13 & 5 \\
\hline & & & $10.1-36.7$ & 45 & 17 \\
\hline \multirow[t]{2}{*}{$3.51-4.0$} & \multirow[t]{2}{*}{ - } & \multirow[t]{2}{*}{10} & $11.4-20$ & - & 26 \\
\hline & & & $20.1-30$ & - & 6 \\
\hline \multirow[t]{2}{*}{$4.01-4.5$} & \multirow[t]{2}{*}{1} & \multirow[t]{2}{*}{3} & 5 & - & 6 \\
\hline & & & $20-28$ & 15 & 6 \\
\hline $4.51-5.0$ & - & 1 & 13.3 & - & 17 \\
\hline \multirow[t]{2}{*}{$5.01-6$} & \multirow[t]{2}{*}{ - } & \multirow[t]{2}{*}{4} & 6 & - & 1 \\
\hline & & & 29 & - & 14 \\
\hline $6.01-7$ & - & 1 & NA & - & 3 \\
\hline
\end{tabular}




\begin{tabular}{|l|l|l|l|l|l|}
\hline & 77 & 33 & & 273 & $137+68$ \\
\hline
\end{tabular}


Table 2. Modifications of the G16 model used to develop the Fenno-G16 GMPE.

\begin{tabular}{|c|c|}
\hline Original G16 & Fenno-G16 adaptation \\
\hline$P G A_{G 16}=G_{1} \cdot G_{2} \cdot G_{3} \cdot C_{\text {mean }}$ & Eliminated \\
\hline$P G A_{2800}=P G A_{G 16} \cdot G_{4}$ & $P G A_{F e n n-G 16}=G_{1} \cdot G_{2} \cdot G_{3}$ \\
\hline$G_{1}=\left[c_{1} \cdot \arctan \left(M_{w}+c_{2}\right)+c_{3}\right] \cdot F$ & $\begin{array}{l}G_{l} \text { formulation remains unchanged, except for } F \text { that is } \\
\text { replaced as follows: } \\
G_{1}=\left[c_{1} \cdot \arctan \left(M_{w}+c_{2}\right)+c_{3}\right] \cdot F_{F e n n o G 16} \\
\text { with } F_{F e n n o-G 16}=F \cdot C_{\text {mean }} \cdot G_{4}=1.1527\end{array}$ \\
\hline$G_{2} \frac{1}{\sqrt{\left[\left(1-\frac{R_{\text {rup }}}{R_{\text {cor }}}\right)^{2}+4 \cdot D_{2}^{2} \cdot \frac{R_{\text {rup }}}{R_{\text {cor }}}\right]}}$ & $\begin{array}{c}G_{2} \frac{1}{\sqrt{\left[\left(1-\left(\frac{R_{\text {rup }}}{R_{\text {cor }}}\right)^{S_{l}}\right)^{2}+1.96 \cdot\left(\frac{R_{\text {rup }}}{R_{\text {cor }}}\right)^{S_{l}}\right]}} \\
\mathrm{R}_{\text {cor }}=\mathrm{c}_{4} \cdot \mathrm{M}_{\mathrm{w}}+\mathrm{c}_{5} \text {, with } c_{4}=4.3686, c_{5}=-9.6702, \\
\text { between } \mathrm{R}_{\text {cor_min }}=4.616 \mathrm{~km} \text { and } \mathrm{R}_{\text {cor_max }}=11.288 \mathrm{~km} . \\
\text { And, } S_{l}=\varepsilon_{1} \cdot M_{w}+\varepsilon_{2}, \\
\text { with } \varepsilon_{1}=-0.1222, \varepsilon_{2}=1.9329\end{array}$ \\
\hline$G_{3}$ & No change \\
\hline$S A(T)_{c o r, 2800}=P G A_{G 16} \cdot S A_{\text {norm }} \cdot \frac{\operatorname{LinAmp} p_{V s 30=2800}}{\operatorname{LinAmp}_{V s 30=640}} \cdot \frac{1}{\operatorname{Res}(T)}$ & $S A(T)_{\text {FennoG } 16}=P G A_{F e n n o-G 16} \cdot S A_{\text {norm }}$ \\
\hline$S A_{\text {norm }}$ & Identical formulation as in $\mathrm{G} 16$, but $I=1.393$. \\
\hline$M M=\left\{\begin{array}{c}5.25-0.4 \cdot\left(5.25-M_{w}\right), M_{w} \leq 5.25 \\
M_{w}, 5.25<M_{w}<7.5 \\
7.5+0.5 \cdot\left(M_{w}-7.5\right), M_{w} \geq 7.5\end{array}\right.$ & $M M=M_{w}$ \\
\hline
\end{tabular}




\begin{tabular}{|c|c|}
\hline$R R=\left\{\begin{array}{c}R_{\text {rup }}, R_{\text {rup }}<600 \\
600+0.5 \cdot\left(R_{\text {rup }}-600\right), 600 \leq R_{\text {rup }} \leq 1000 \\
800+0.2 \cdot\left(R_{\text {rup }}-1000\right), R_{\text {rup }}>1000\end{array}\right.$ & $R R=R_{\text {rup }}$ \\
\hline$S=s_{1} \cdot R R-\left(s_{2} \cdot M M+s_{3}\right)$ & $\begin{array}{l}\text { Identical, but with the new } M M \text { and } R R \text { definitions and } \\
\qquad S_{3}=0.422 .\end{array}$ \\
\hline$\xi=a_{1} \cdot M_{w}{ }^{2}+a_{2} \cdot M_{w}+a_{3}$ & $\xi=2.027$ \\
\hline$T_{s p, 0}=t_{1} \cdot R R+t_{2} \cdot M M+t_{3}$ & $\begin{array}{c}T_{s p, 0}=\max \left(t_{1} \cdot R R+t_{2} \cdot M M+t_{3}, T_{s p, 0, \max }\right) \\
T_{s p, 0, \max }=2 \cdot \exp (-\mu)\end{array}$ \\
\hline$\mu=m_{1} \cdot R R+m_{2} \cdot M M+m_{3}$ & $\begin{array}{c}\text { Identical formulation, } \\
\text { but: } m_{2}=-0.1584 \text { and } m_{3}=3.5756\end{array}$ \\
\hline LinAmp correction in Eq. 8 & Eliminated \\
\hline Residual correction in Eq. 8 & Eliminated \\
\hline
\end{tabular}

GMPE $=$ ground-motion prediction equation, $\mathrm{PGA}=$ peak ground acceleration, $G_{1}=$ magnitudescaling filter, $G_{2}=$ distance attenuation factor, $G_{3}=$ anelastic attenuation filter, $G_{4}=$ site correction filter, $\mathrm{I}=$ intensity controlling the amplification $\mathrm{M}_{\mathrm{w}}=$ moment magnitude, $\mathrm{R}_{\text {rup }}=$ rupture distance, $\mathrm{R}_{\text {cor }}=$ corner distance, $\mathrm{SA}=$ spectral acceleration, $\mathrm{SA}_{\text {norm }}=$ standard spectral shape, $\mathrm{S}_{1}=$ slope factor, Res = residual, $\mathrm{MM}=$ modified magnitude, $\mathrm{RR}=$ distance, $\mathrm{T}=$ spectral period, $\mathrm{v}_{\mathrm{s}}=$ shearwave velocity, LinAmp = site amplification function. 
Table 3. Median and standard deviations $(\sigma)$ of the residuals $(\ln (\operatorname{Res}))$ of the proposed normal spectral shape $\left(\mathrm{SA}_{\text {norm}}\right)$.

\begin{tabular}{|c|c|c|c|c|c|c|c|c|c|}
\hline $\mathbf{f}(\mathbf{H z})$ & $\mathbf{0 . 1}$ & $\mathbf{0 . 5}$ & $\mathbf{1}$ & $\mathbf{2}$ & $\mathbf{5}$ & $\mathbf{1 0}$ & $\mathbf{1 5}$ & $\mathbf{2 0}$ & $\mathbf{4 0}$ \\
\hline Median & -0.329 & -0.14 & -0.020 & -0.109 & -0.038 & -0.000 & -0.047 & -0.067 & -0.238 \\
\hline$\sigma$ & 1.43 & 1.06 & 0.82 & 0.80 & 0.66 & 0.45 & 0.33 & 0.27 & 0.36 \\
\hline
\end{tabular}


Table 4. Median and standard deviations $(\sigma)$ of the residuals $(\ln (\operatorname{Res}))$ of the Fenno-G16 groundmotion prediction equation (GMPE).

\begin{tabular}{|c|c|c|c|c|c|c|c|c|c|c|}
\hline $\mathbf{f}(\mathbf{H z})$ & $\mathbf{0 . 1}$ & $\mathbf{0 . 5}$ & $\mathbf{1}$ & $\mathbf{2}$ & $\mathbf{5}$ & $\mathbf{1 0}$ & $\mathbf{1 5}$ & $\mathbf{2 0}$ & $\mathbf{4 0}$ & $\mathbf{P G A}$ \\
\hline Median & -0.529 & -0.306 & -0.050 & -0.113 & -0.057 & 0.033 & -0.039 & -0.038 & -0.267 & -0.014 \\
\hline$\sigma$ & 1.30 & 0.93 & 0.77 & 0.75 & 0.73 & 0.76 & 0.81 & 0.86 & 0.87 & 0.80 \\
\hline
\end{tabular}

PGA = peak ground acceleration 
Table 5. Standard deviations $(\sigma)$ of the residuals $(\ln (\operatorname{Res}))$ of the Fenno-G16 ground-motion prediction equation (GMPE) for different magnitude ranges.

\begin{tabular}{|c|c|c|c|c|c|c|c|c|c|c|}
\hline $\mathbf{f}(\mathbf{H z})$ & $\mathbf{0 . 1}$ & $\mathbf{0 . 5}$ & $\mathbf{1}$ & $\mathbf{2}$ & $\mathbf{5}$ & $\mathbf{1 0}$ & $\mathbf{1 5}$ & $\mathbf{2 0}$ & $\mathbf{4 0}$ & PGA \\
\hline$\sigma_{\mathrm{Mw} 2-2.6}$ & 1.11 & 0.76 & 0.62 & 0.67 & 0.62 & 0.65 & 0.71 & 0.80 & 0.85 & 0.78 \\
\hline$\sigma_{\mathrm{Mw} 2.6-3.5}$ & 1.16 & 0.82 & 0.74 & 0.71 & 0.73 & 0.72 & 0.78 & 0.82 & 0.86 & 0.75 \\
\hline$\sigma_{\mathrm{Mw} 3.5-5}$ & 0.86 & 0.86 & 0.84 & 0.83 & 0.80 & 0.85 & 0.94 & 0.98 & 0.93 & 0.87 \\
\hline$\sigma_{\mathrm{Mw} 5-7}$ & 0.94 & 1.02 & 0.97 & 0.85 & 0.84 & 0.79 & 0.69 & 0.71 & 0.58 & 0.71 \\
\hline
\end{tabular}

PGA = peak ground acceleration, $\mathrm{M}_{\mathrm{w}}=$ moment magnitude 
Table 6. Standard deviations of the residuals $(\ln (\operatorname{Res}))$ at stations with at least 20 recordings.

\begin{tabular}{|l|c|c|c|c|c|c|c|c|c|c|c|c|c|}
\hline Station & \multirow{2}{*}{ Rec. } & \multicolumn{9}{|c|}{ (Hz) } \\
\cline { 3 - 16 } & & $\mathbf{0 . 1}$ & $\mathbf{0 . 5}$ & $\mathbf{1}$ & $\mathbf{2}$ & $\mathbf{5}$ & $\mathbf{1 0}$ & $\mathbf{1 5}$ & $\mathbf{2 0}$ & $\mathbf{3 3 . 3 3}$ & $\mathbf{4 0}$ & $\mathbf{1 0 0}$ & PGA \\
\hline OUL & 24 & 1.13 & 0.65 & 0.58 & 0.57 & 0.63 & 0.59 & 0.55 & 0.54 & 0.48 & 0.43 & - & 0.46 \\
\hline RNF & 20 & 0.89 & 0.51 & 0.6 & 0.68 & 0.51 & 0.6 & 0.52 & 0.51 & 0.50 & 0.47 & - & 0.47 \\
\hline TOF & 20 & 1.06 & 0.67 & 0.52 & 0.65 & 0.61 & 0.55 & 0.57 & 0.55 & 0.47 & 0.42 & - & 0.48 \\
\hline
\end{tabular}

$\mathrm{PGA}=$ peak ground acceleration, $\mathrm{OUL}=\mathrm{Oulu}, \mathrm{RNF}=$ Rovaniemi, $\mathrm{TOF}=$ Tornio 


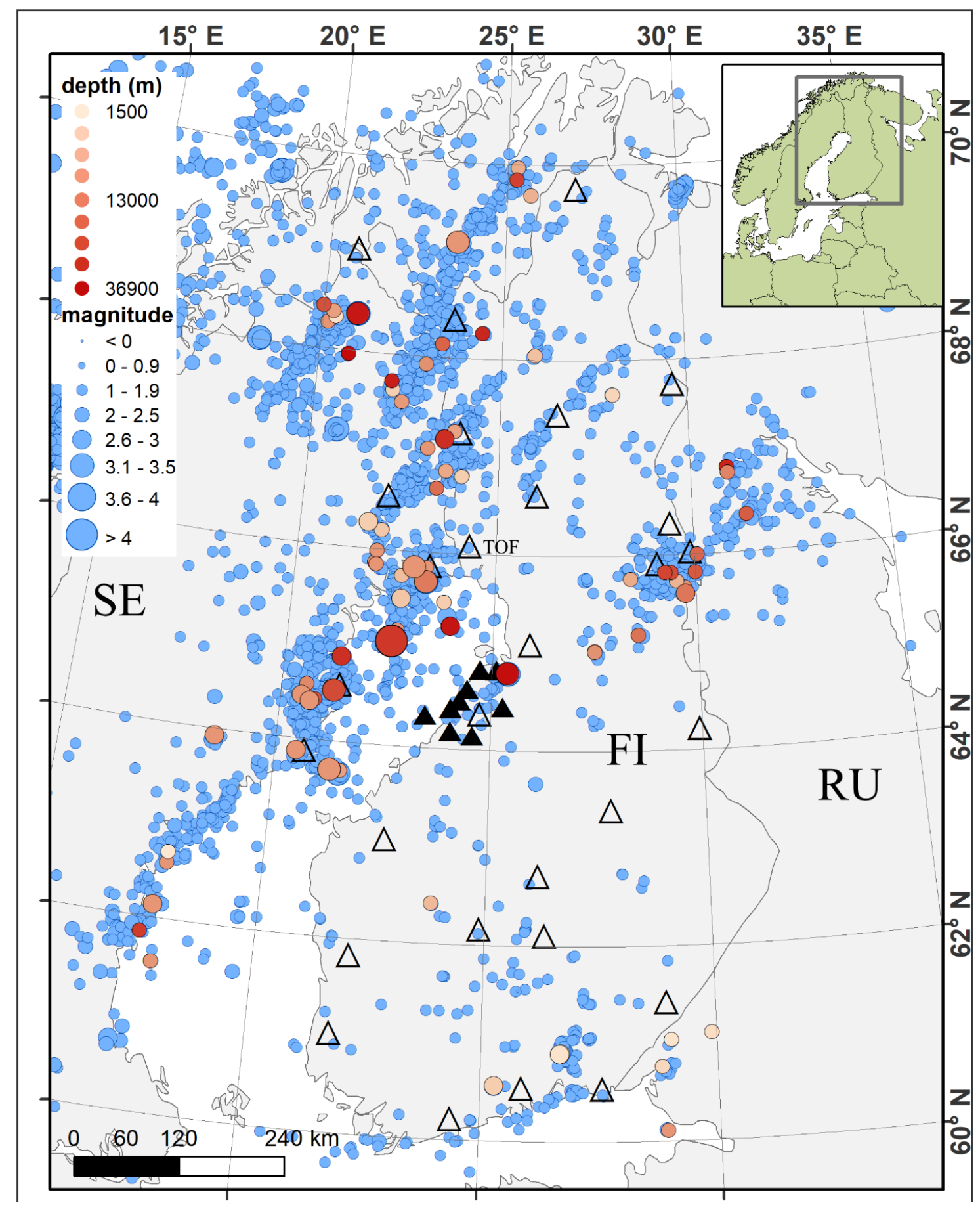

Figure 1. Epicenters of the Fennoscandian dataset between 2006 and 2018. The red dots show earthquakes with local magnitude $\mathrm{M}_{\mathrm{L}} \geq 2$ accepted for the final analysis, and the blue dots are smaller earthquakes. The triangles denote the seismic stations 
where data were obtained at 100 or $250 \mathrm{~Hz}$ sampling rates. The filled triangles comprise the network in the province of Ostrobothnia, Finland (OBF), which operates around the planned nuclear power plant site. FI, Finland; RU, Russia; SE, Sweden; TOF seismic station Tornio

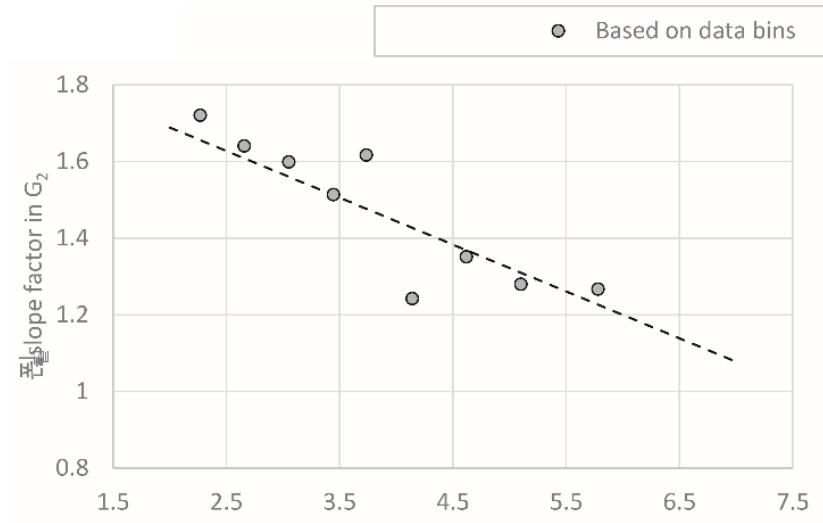

(a)

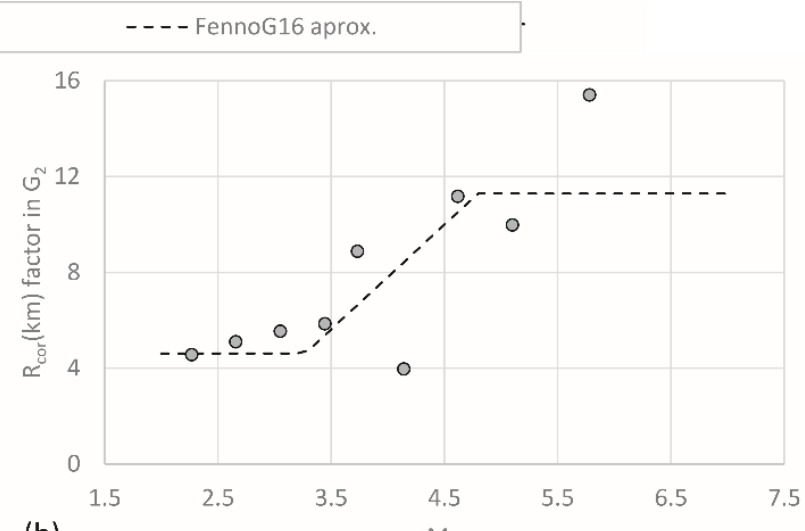

(b)

Figure 2. Distance attenuation filter $G_{2}$ controlling the extent of the peak ground acceleration (PGA) plateau and the slope, fitted to the available data. The earthquakes were binned at moment magnitude $\mathrm{M}_{\mathrm{w}} 0.4$ intervals, and the best fits to the $G_{2}$ filter parameters were determined by regression. The values calculated from data in each magnitude bin are marked with as gray circles, while the approximation used in Fenno-G16 is shown as dashed lines for the (a) slope factor $S_{l}$ and (b) corner distance $R_{\text {cor }}$, respectively. 


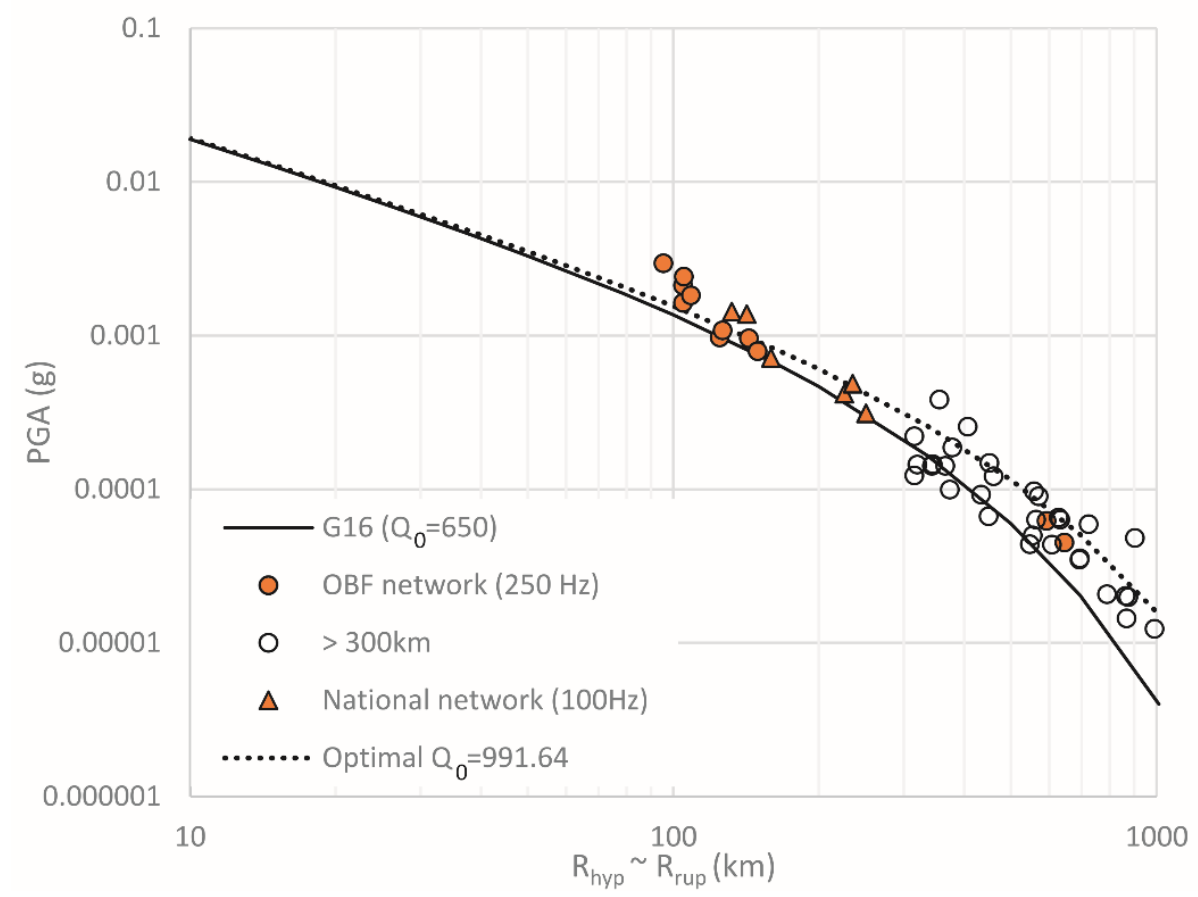

Figure 3. Comparison of the Graizer (2016; hereafter, G16) prediction with the Fennoscandian data within their validity range, using the original parameters and regional quality factor $\mathrm{Q}_{0}=650$ (solid line) and optimized $\mathrm{Q}_{0}=991.64$ (dotted line). The recordings at the local seismic network in OBF (filled circles) and at the single seismic stations of the national network (filled triangles) are shown. The open circles are recordings at distances over $300 \mathrm{~km}$ and are outside the calibration range. $R_{\mathrm{hyp}}$, hypocentral distance; $R_{\text {rup }}$, rupture distance. 
(a)

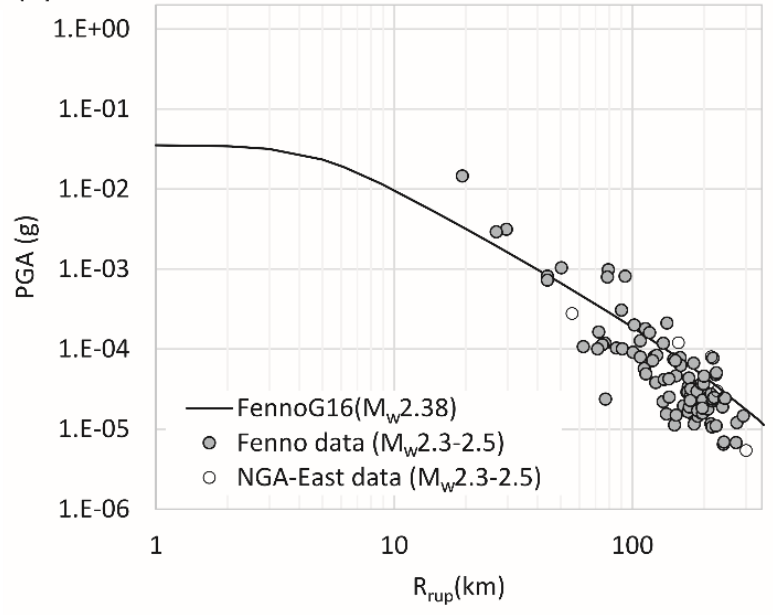

(c)

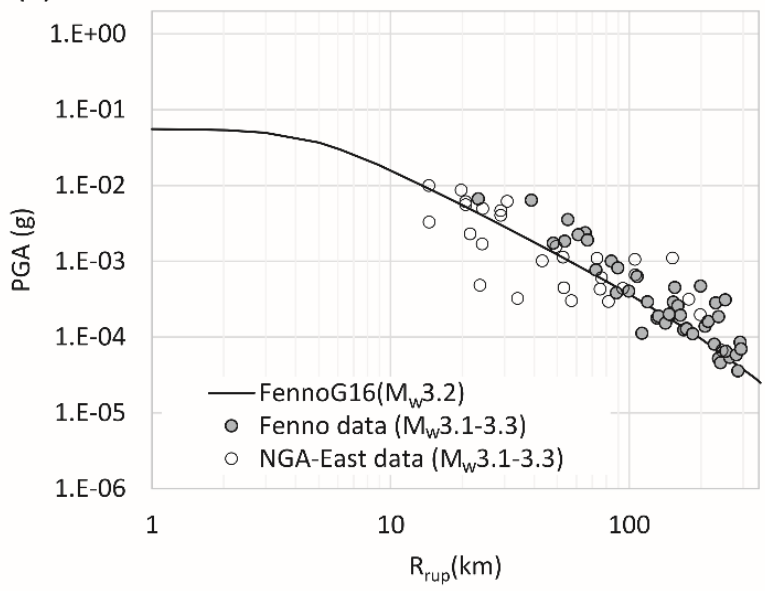

(e)

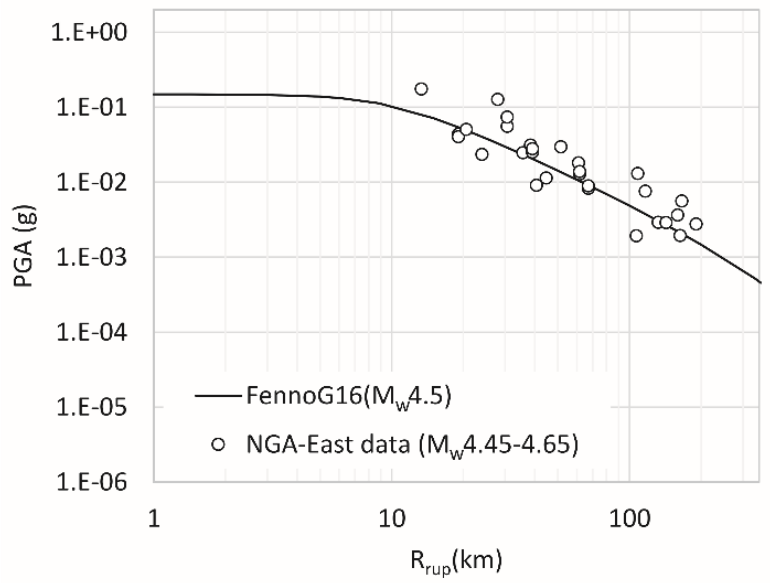

(b)

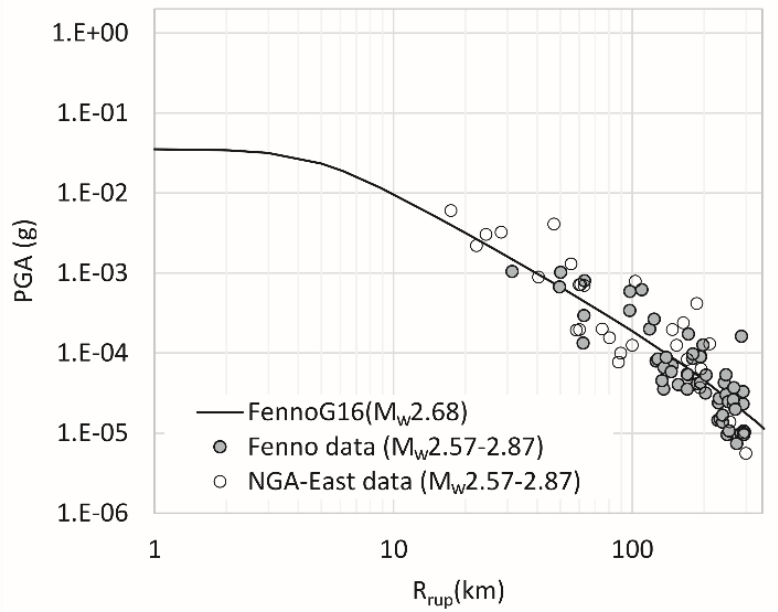

(d)

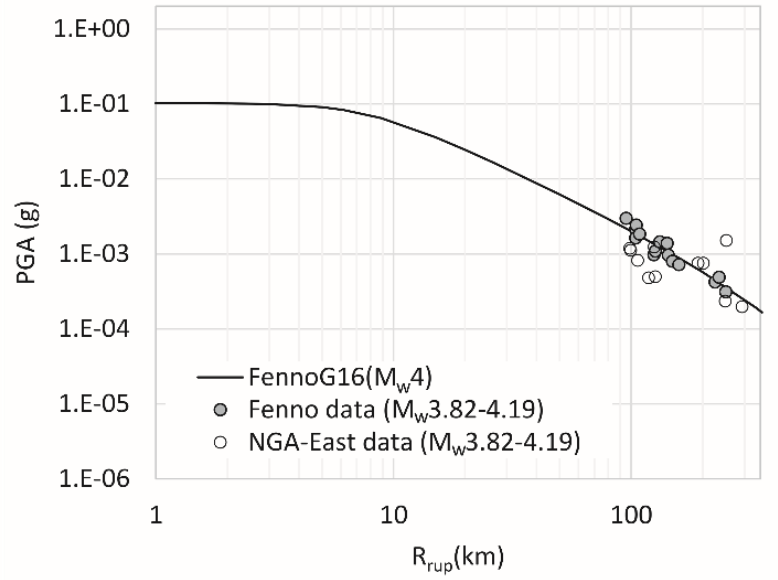

(f)

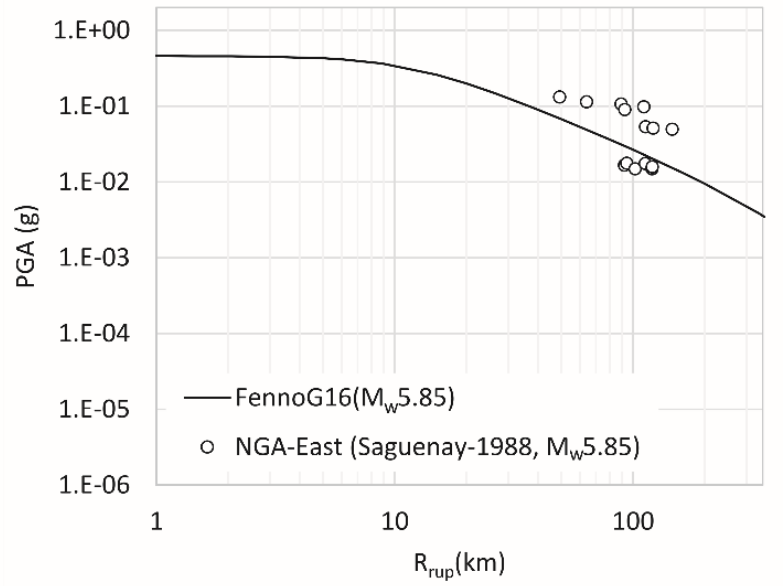


Figure 4. Comparison of the Fenno-G16 prediction developed (solid line) with recorded PGAs at specified magnitude intervals. Data plotted in the magnitude ranges (a) $M_{\mathrm{w}} 2.3-2.5$, (b) $M_{\mathrm{w}} 2.57-2.87$, (c) $M_{\mathrm{w}} 3.1-3.3$, (d) $M_{\mathrm{w}} 3.82-4.19$, (e) $M_{\mathrm{w}}$ 4.45-4.65, and (f) $M_{\mathrm{w}} 5.85$, with the corresponding Fenno-G16 prediction of the median magnitude of the bin. The filled circles are the Fennoscandian, and the open circles are the Next-Generation Attenuation for CENA (NGA-East) data points. The original parameters of the G16 prediction are used, except for regional quality factor $\left(\mathrm{Q}_{0}\right)$ and the distance attenuation factor $\left(G_{2}\right)$ term, which is modified. $M_{\mathrm{w}}$, moment magnitude; $R_{\text {rup }}$, rupture distance. 

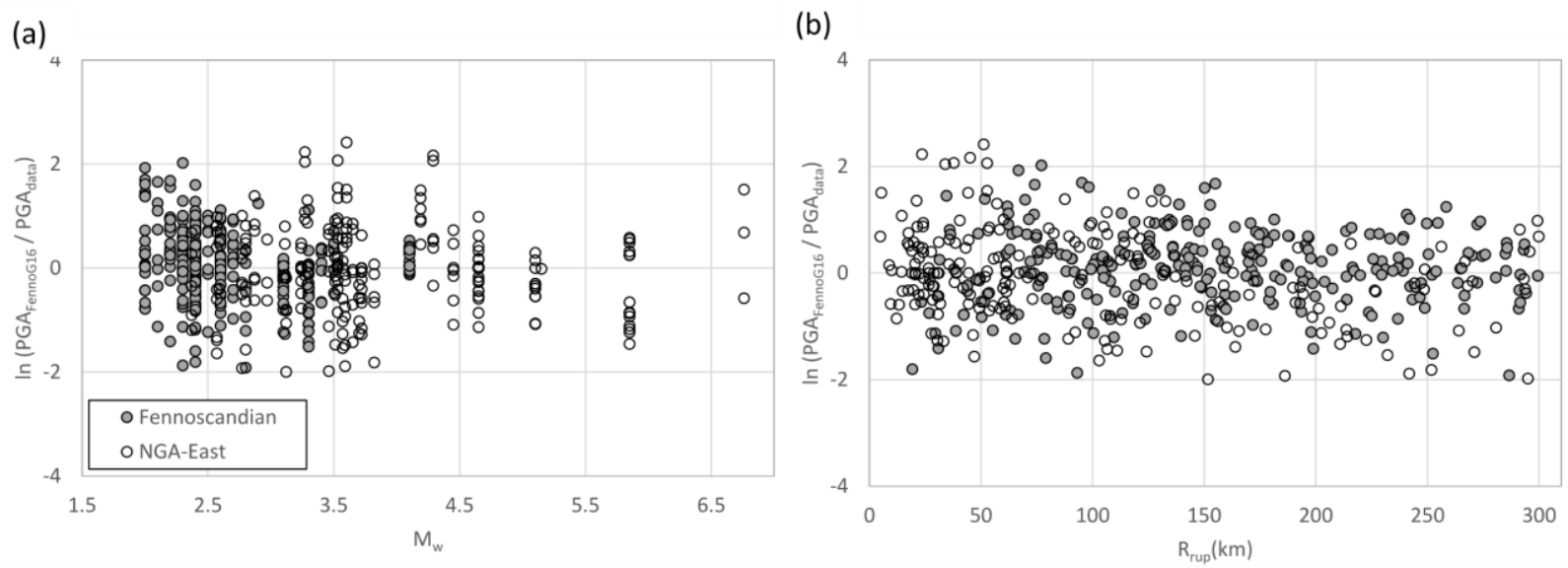

Figure 5. Error in the prediction of PGA and distribution of the error with a) magnitude and b) distance. The filled circles are the Fennoscandian and the open circles the NGA-East data points on hard rock. The mean error is close to zero. 


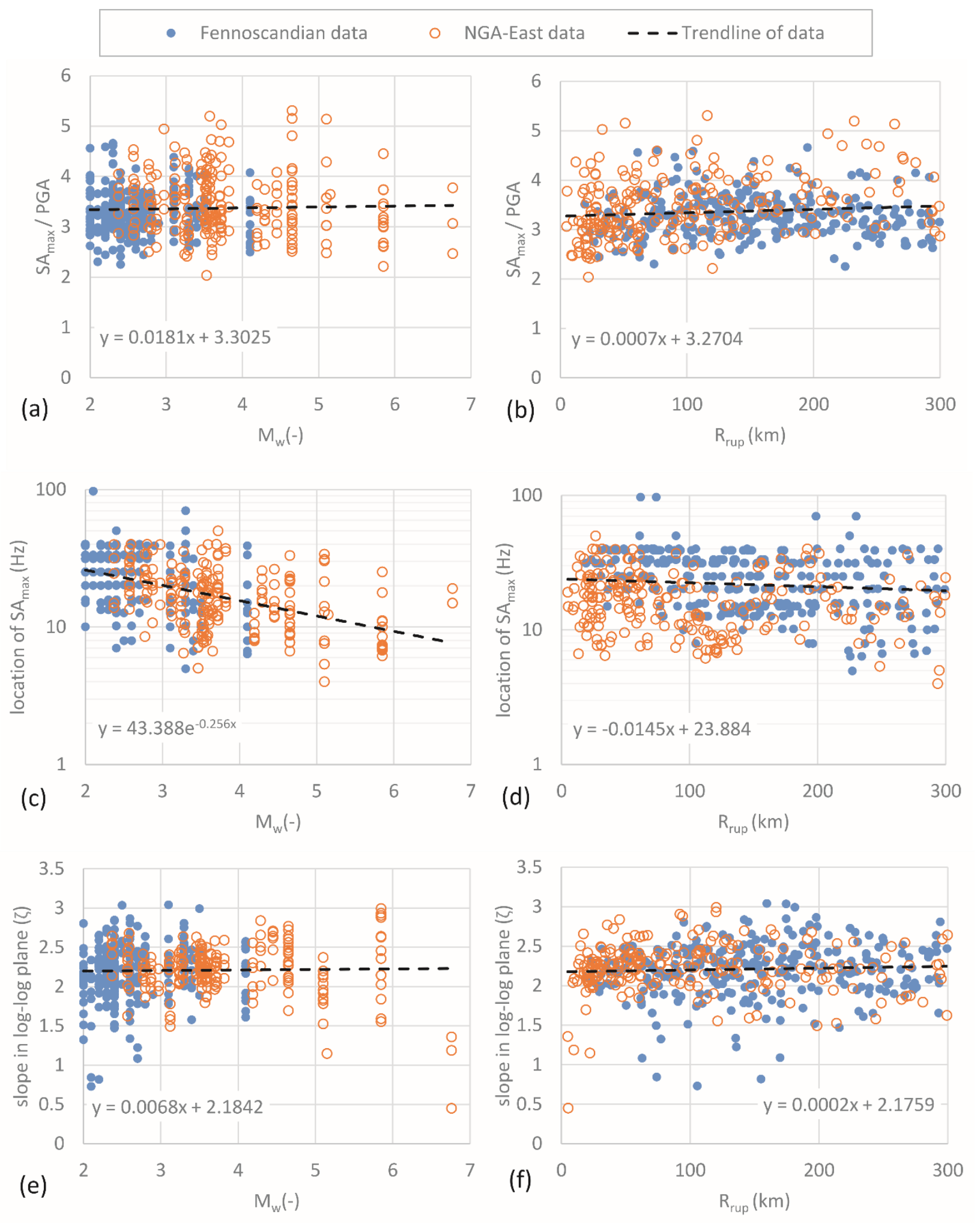


Figure 6. Summary of the main control parameters characterizing the shape of the acceleration spectra as a function of magnitude and distance of the Fennoscandian dataset (blue circles) and the NGA-East subset (orange circles): (a, b) amplification maximum spectral shape/peak ground acceleration $\left(\mathrm{SA}_{\max } / \mathrm{PGA}\right)$ with a mean of $\sim 3$; $(c, d)$ the frequency of the spectral peak; and $(e, f)$ the slope of the spectra at lower frequencies. Best-fit lines and the respective equations illustrate the trends. 


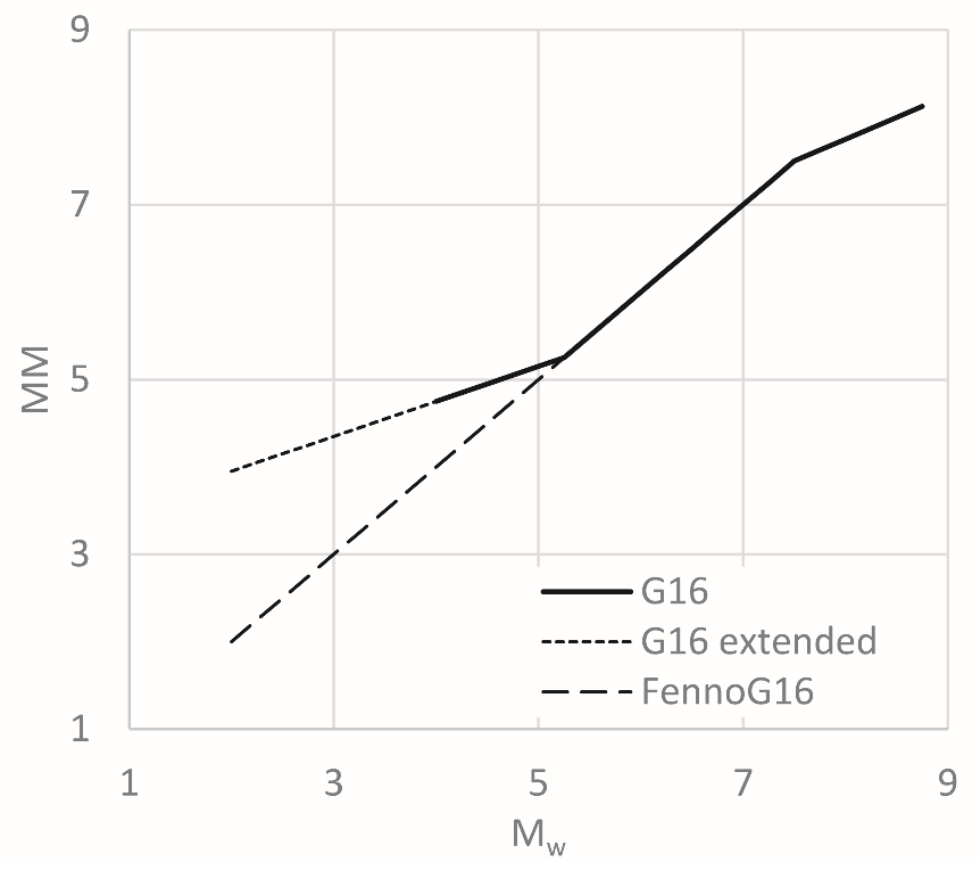

Figure 7. Relationship between moment magnitude $\left(\mathrm{M}_{\mathrm{w}}\right)$ and modified magnitude (MM). The solid line shows the original G16 definition of MM, valid down to $M_{w}$ 4. The short dashes show the original relationship extended down to $M_{w} 2$, and the long dashes show the relationship used in the Fenno-G16 ground-motion prediction equation (GMPE) adaptation. 

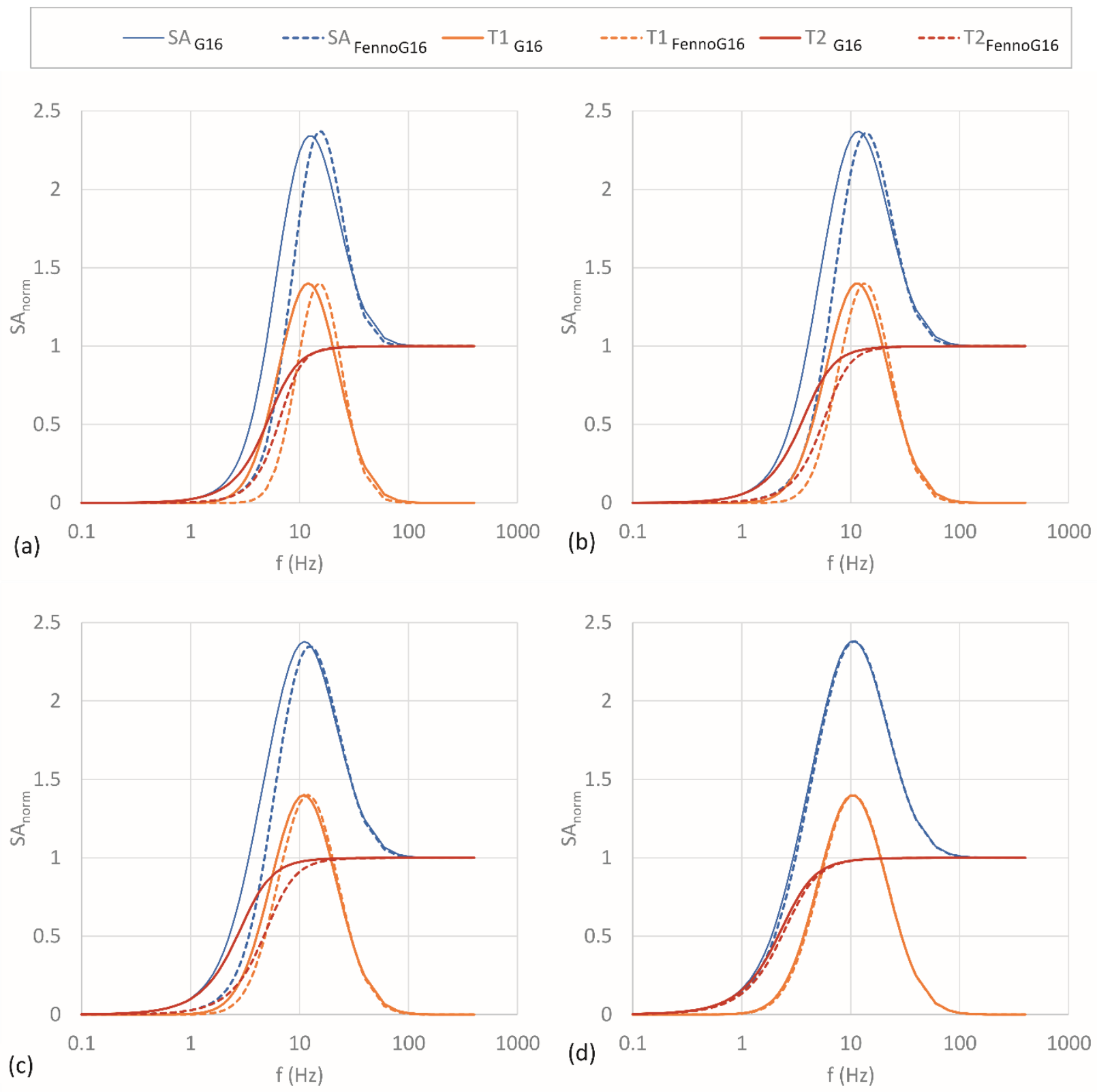

Figure 8. Normalized spectral shape $\left(\mathrm{SA}_{\text {norm }}\right)$ of the $\mathrm{G} 16$ prediction from equation (10) for (a) moment magnitude $\mathrm{M}_{\mathrm{w}}=2$, (b) $\mathrm{M}_{\mathrm{w}} 3$, (c) $\mathrm{M}_{\mathrm{w}}$ 4, and (d) $\mathrm{M}_{\mathrm{w}}$ 5, all with rupture distance $\left(R_{\text {rup }}\right)<600 \mathrm{~km}$ and distance $(\mathrm{RR})=20 \mathrm{~km}$. The solid lines show the extension of the original G16 values to $\mathrm{M}_{\mathrm{w}} 2$ without adaptation, and the dashed lines are the spectral shape with the MM definition. 
(a)

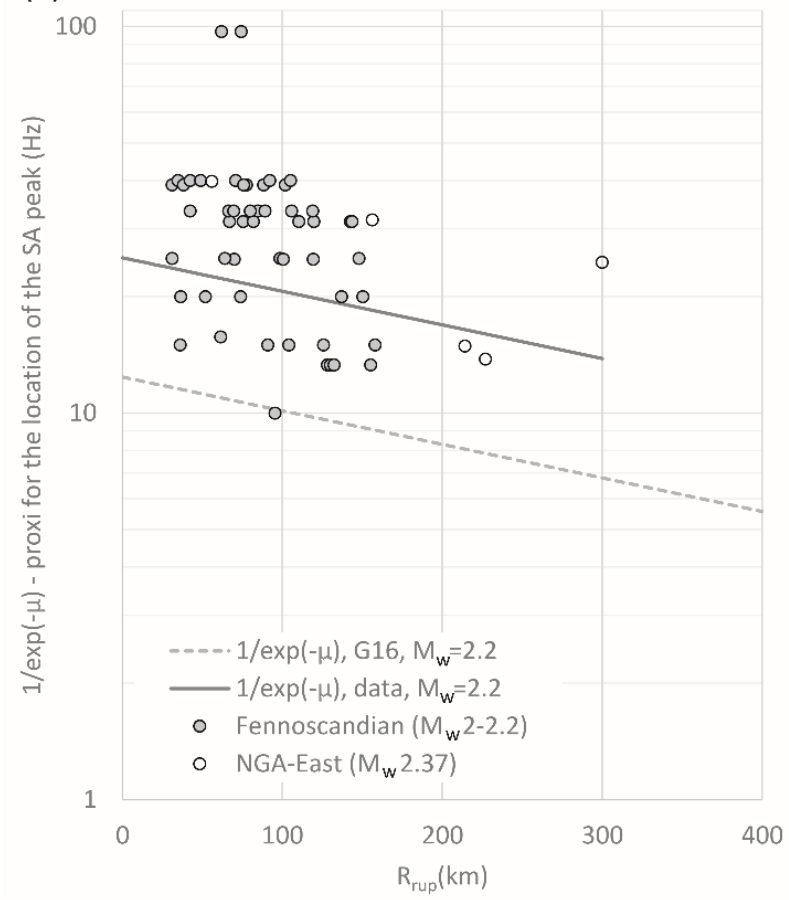

(c)

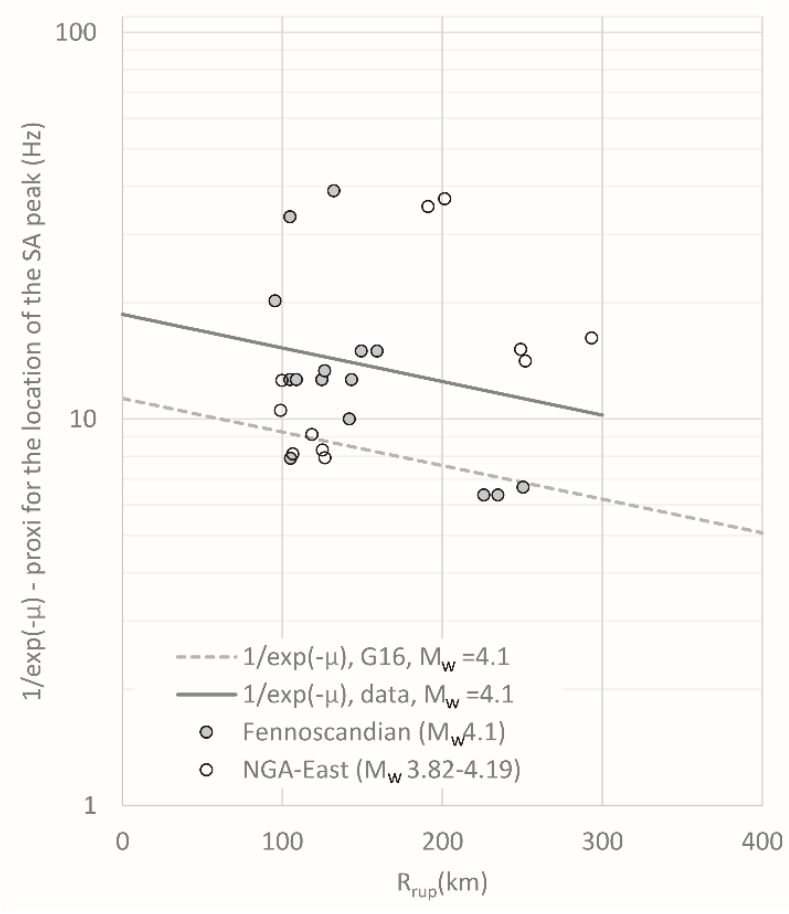

(b)

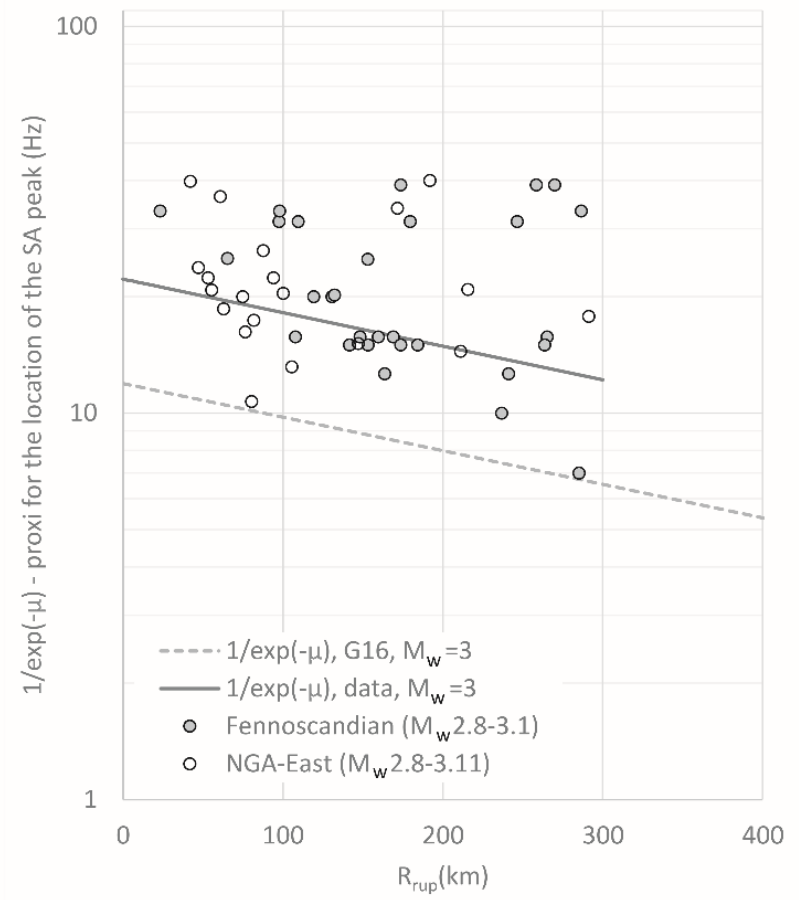

(d)

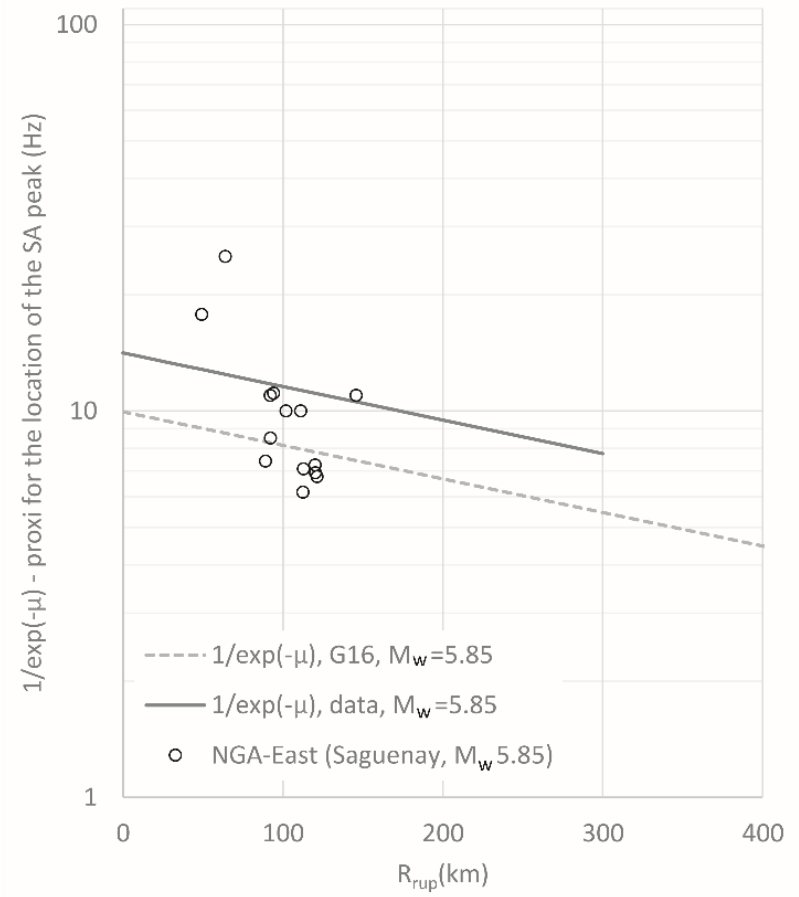

Figure 9. Position of the spectral peak in terms of frequency for four selected magnitudes. The filled circles are the Fennoscandian, and the open circles are the 
NGA-East values. The dashed gray line is the original G16 formulation, hypothetically extended to moment magnitude $\mathrm{M}_{\mathrm{w}} 2$. The solid gray line is the proposed formulation. SA, spectral acceleration. 
(a)

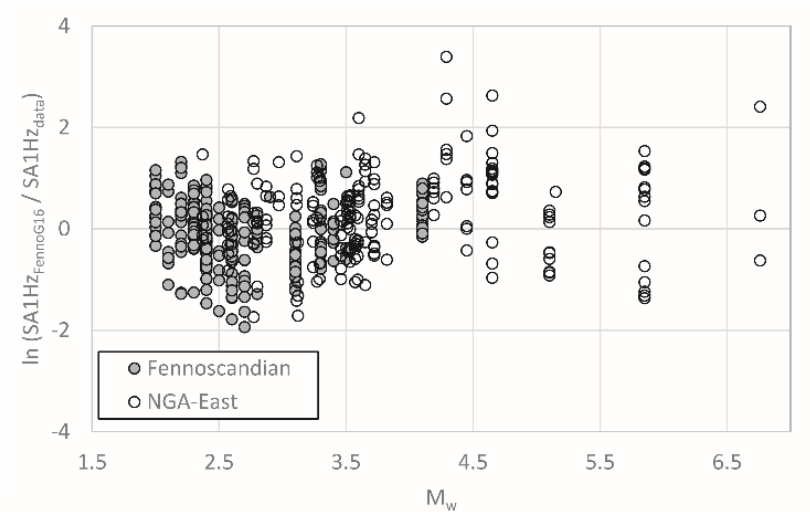

(c)

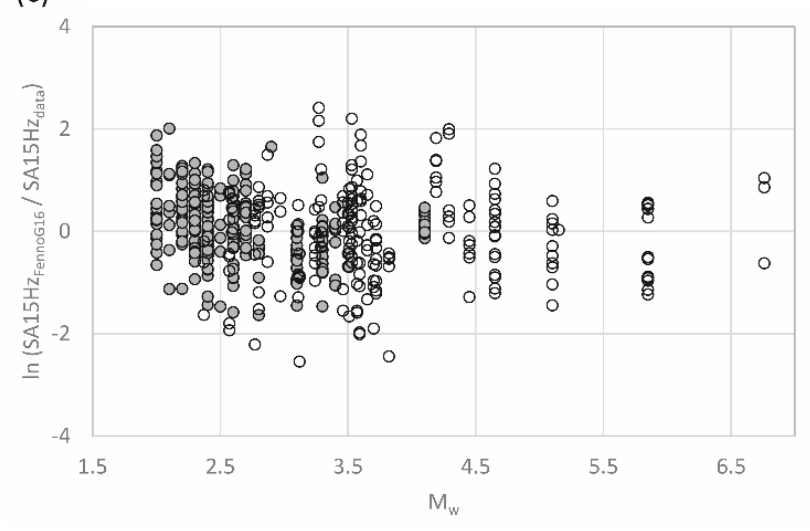

(b)

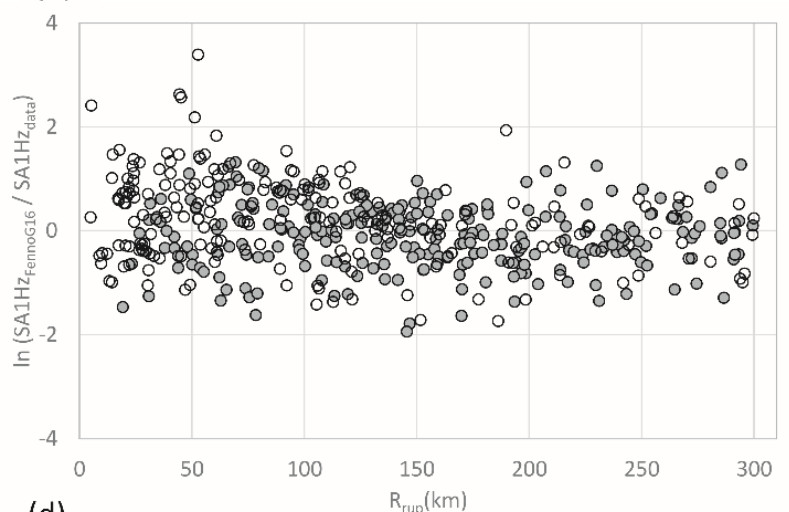

(d)

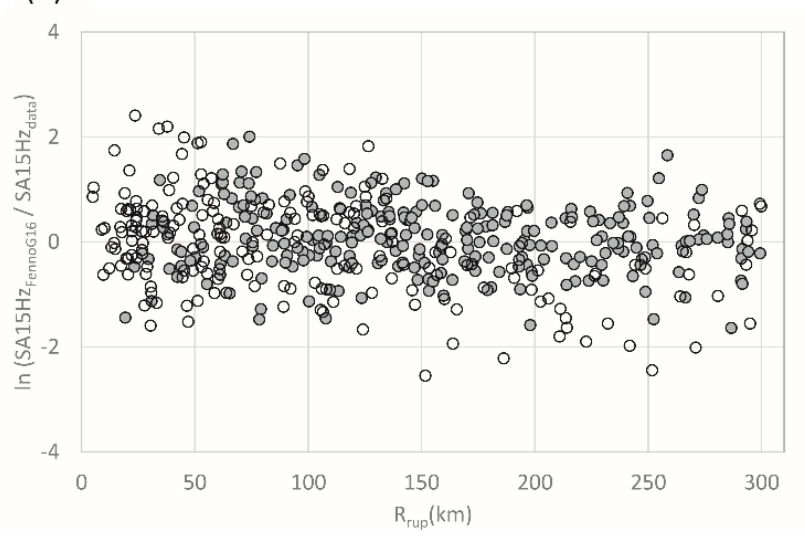

Figure 10. Error in the prediction of the spectra at (a,b) $1 \mathrm{~Hz}$ and (c,d) $15 \mathrm{~Hz}$, and distribution of the error with magnitude and distance. The filled circles are the Fennoscandian and the open circles the NGA-East data points on hard rock. The mean error is close to zero. 
(a)

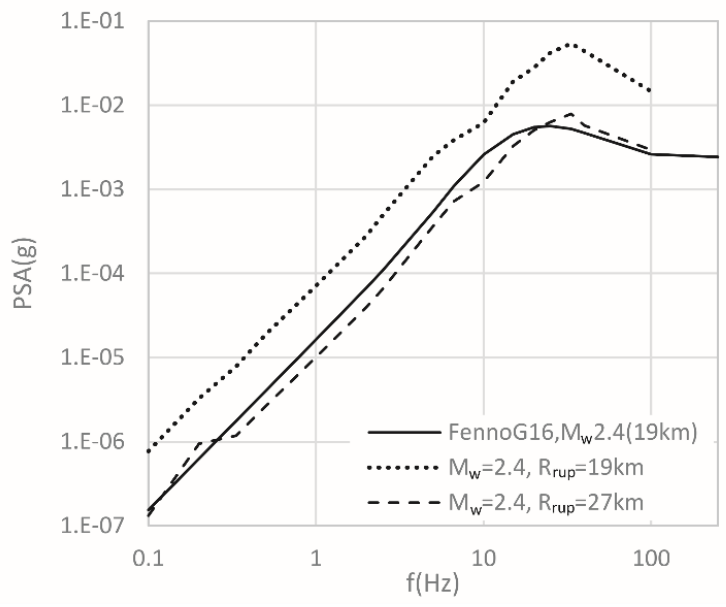

(c)

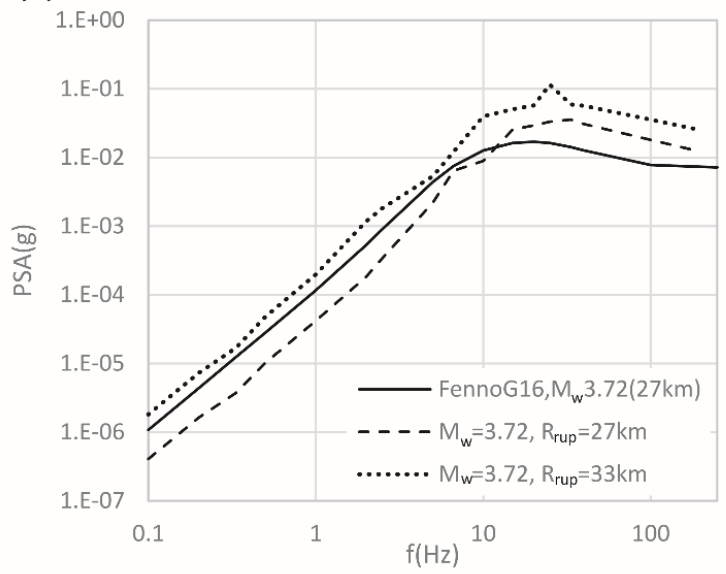

(e)

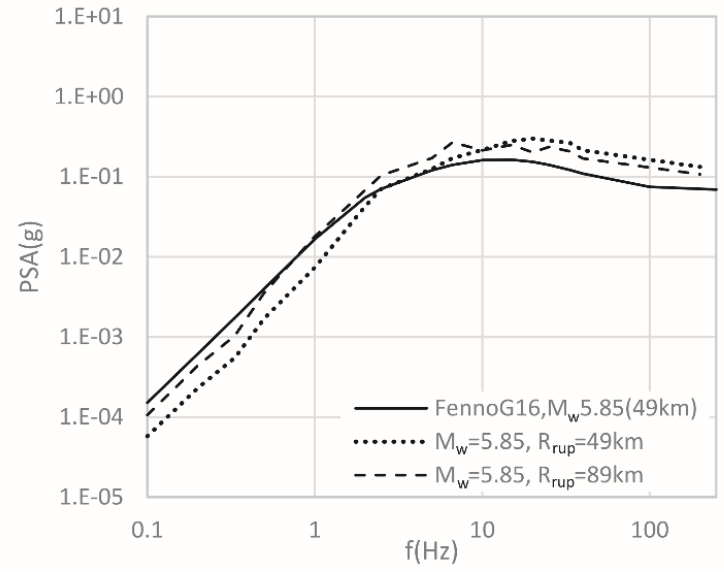

(b)

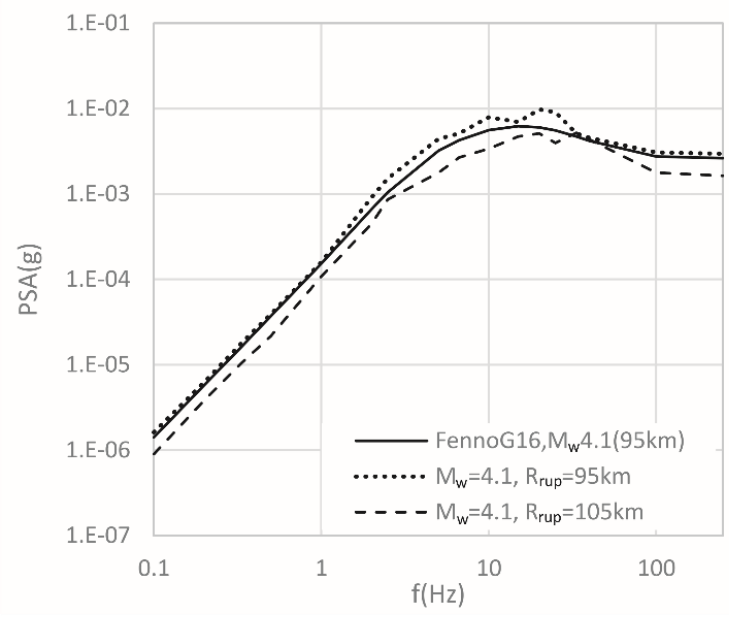

(d)

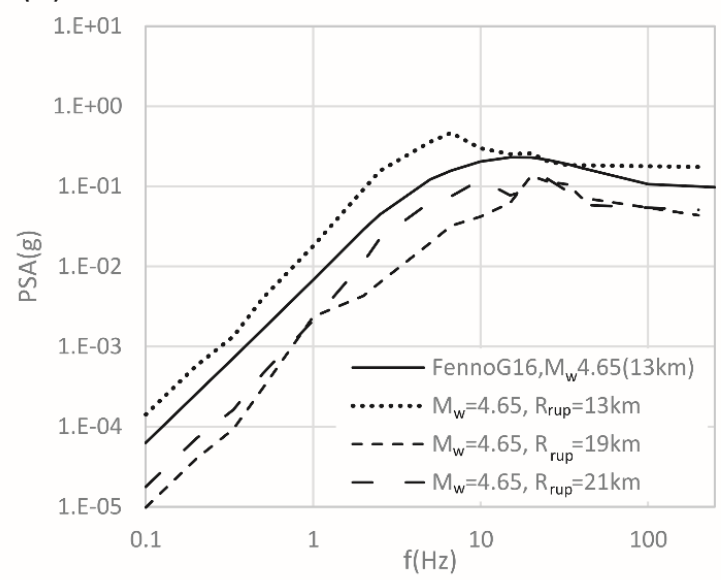

(f)

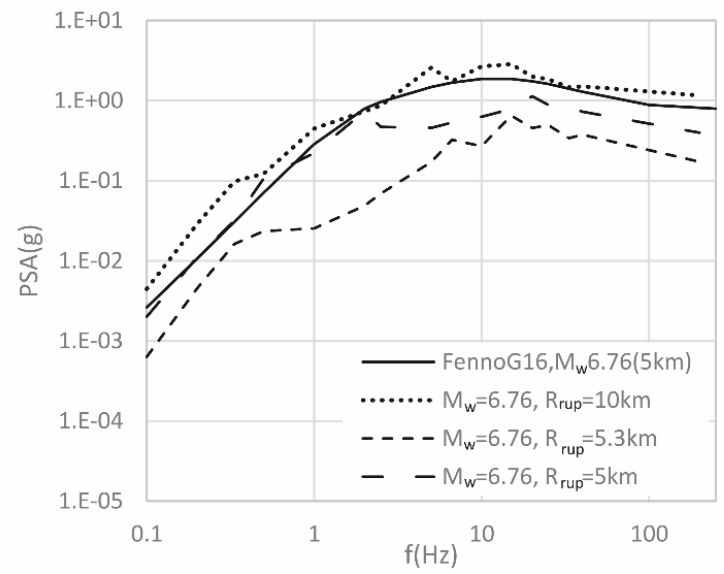

Figure 11. Comparison between the spectra closest to the epicenters and the predicted spectra, for the earthquakes in Fennoscandia on (a) 27 September 2008, in 
Russia close to the border of Finland; b) 19 March 2016 in the Gulf of Bothnia, Sweden; and in North America on (c) 7 April 2006 at Baie St. Paul; (d) 6 March 2005 at Riviere Du Loup; (e) 25 November 1988 at Saguenay; and (f) 23 December 1985 at Nahanni. PSA, pseudospectral acceleration. 

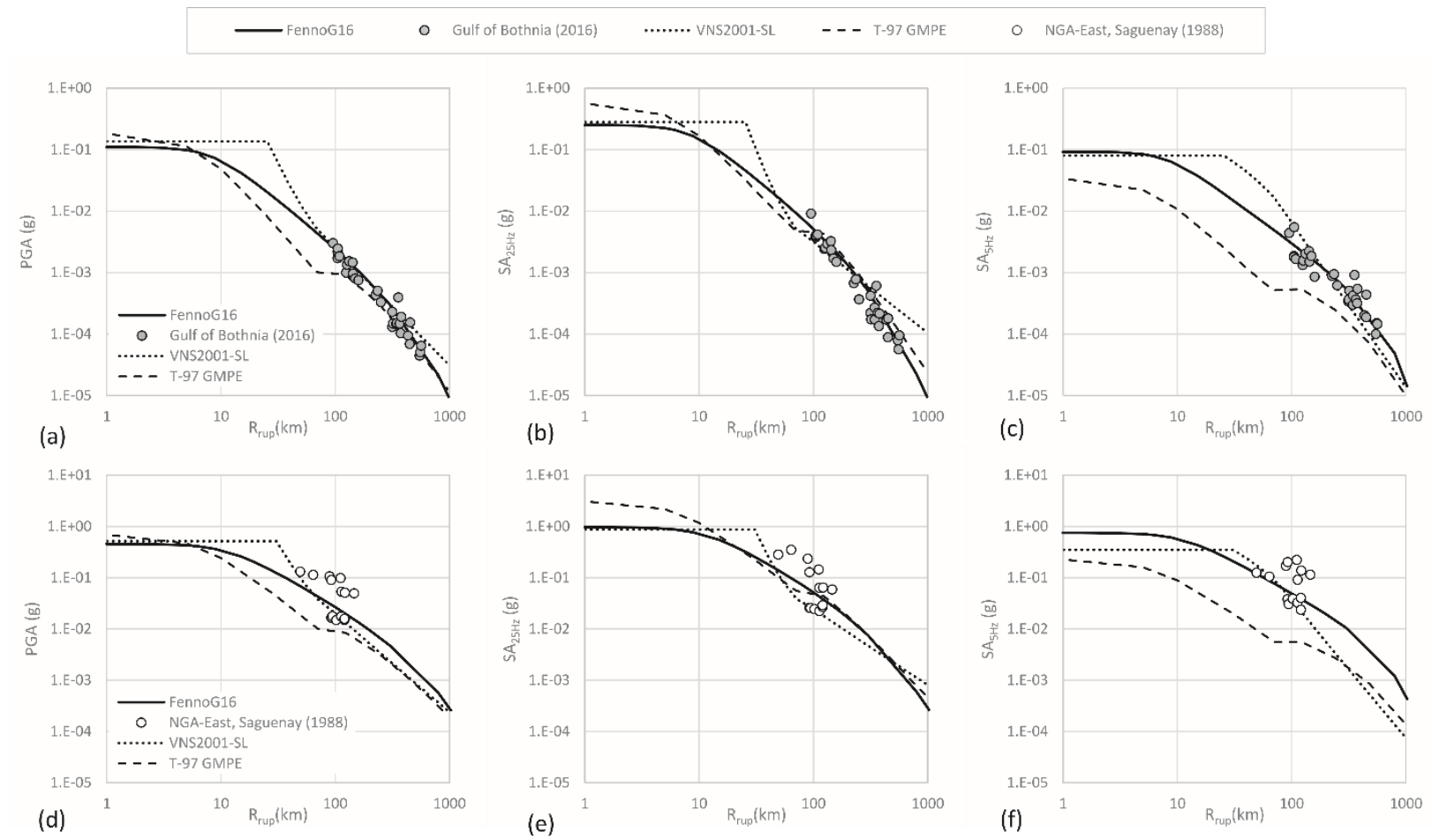

Figure 12. Comparison of PGA and SA at $25 \mathrm{~Hz}$ and $5 \mathrm{~Hz}$ predicted by the FennoG16 GMPE developed in this investigation with the GMPEs by Varpasuo et al. (2001; referred to as VNS2001) and Vuorinen et al. (2018; referred to as T-97) for the (a-c) 19 March 2016 Gulf of Bothnia earthquake (local magnitude $\mathrm{M}_{\mathrm{L}} 4.1, \mathrm{~d}=$ $23.5 \mathrm{~km}$, filled circles) and the (d-f) Saguenay earthquake of 25 November 1988 (moment magnitude $\mathrm{M}_{\mathrm{w}} 5.8, \mathrm{~d}=29 \mathrm{~km}, \mathrm{~d}-\mathrm{f}$, open circles). SL stands for Saguenay longitudinal component at (a,d) $97 \mathrm{~Hz}$, (b,e) $25 \mathrm{~Hz}$, and (c,f) $5 \mathrm{~Hz}$. 
(a)

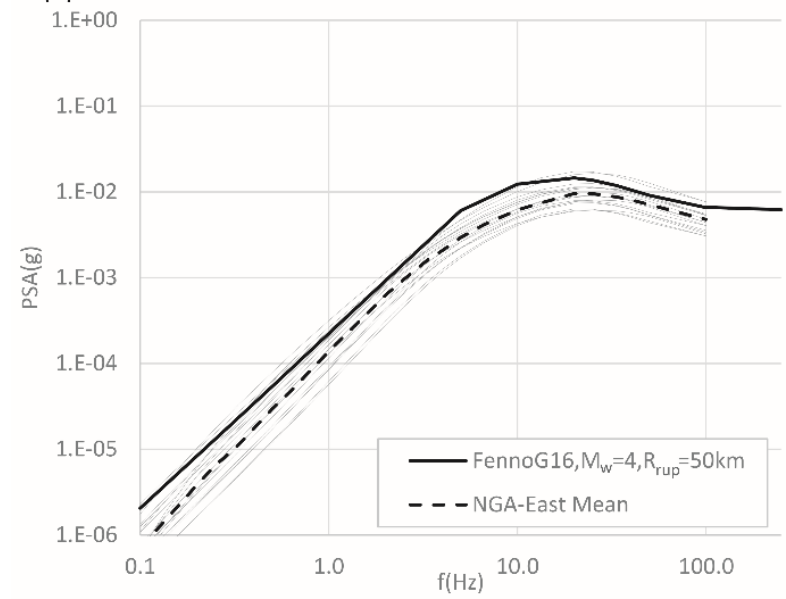

(c)

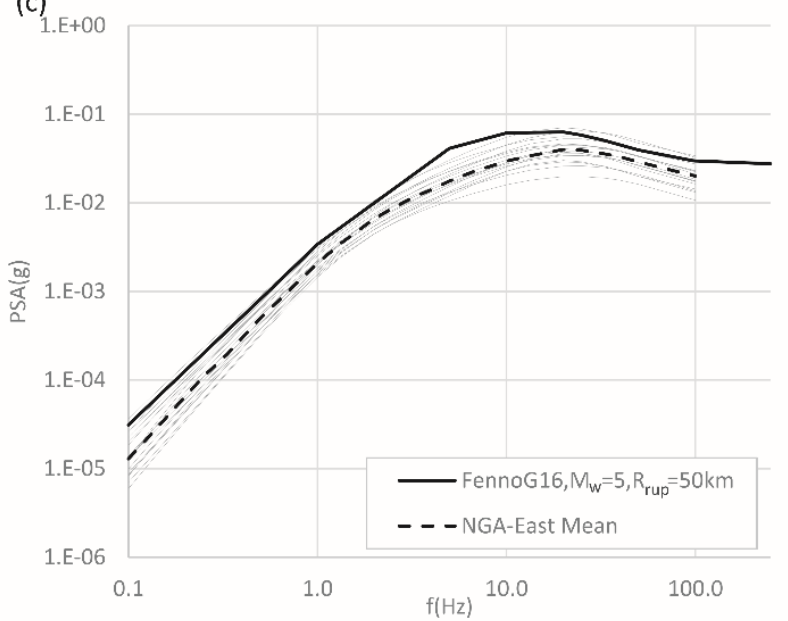

(e)

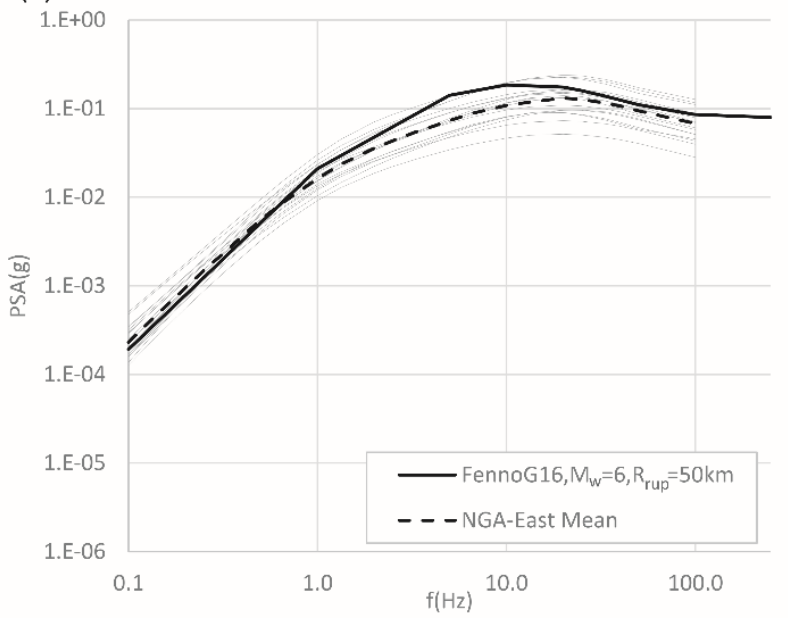

(b)

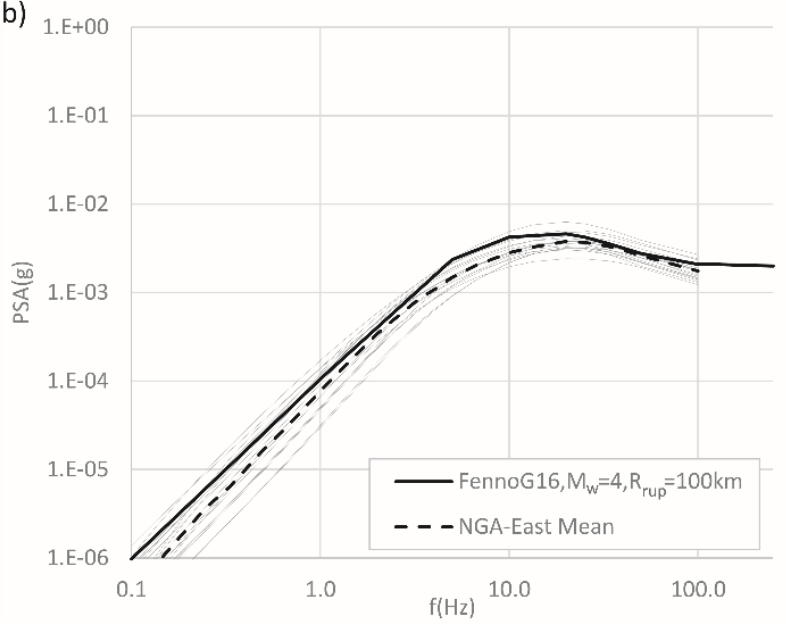

(d)

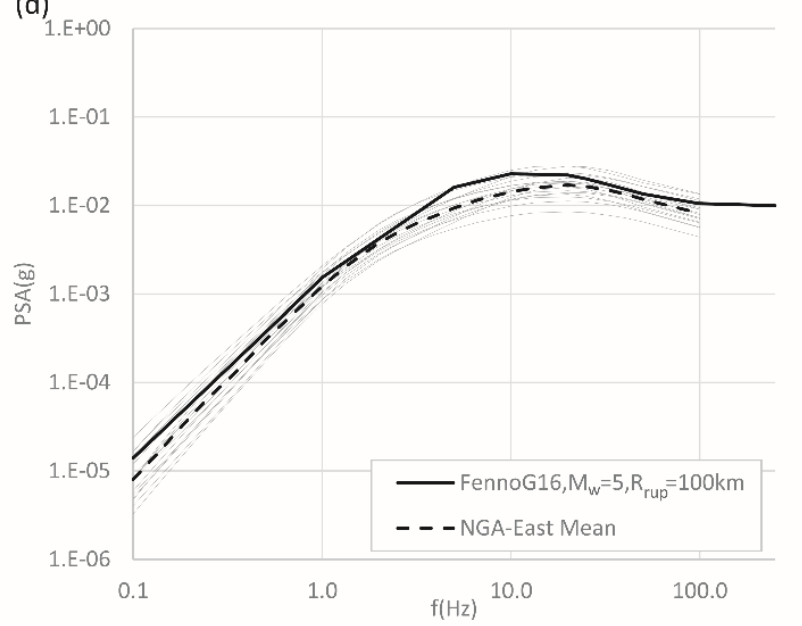

(f)

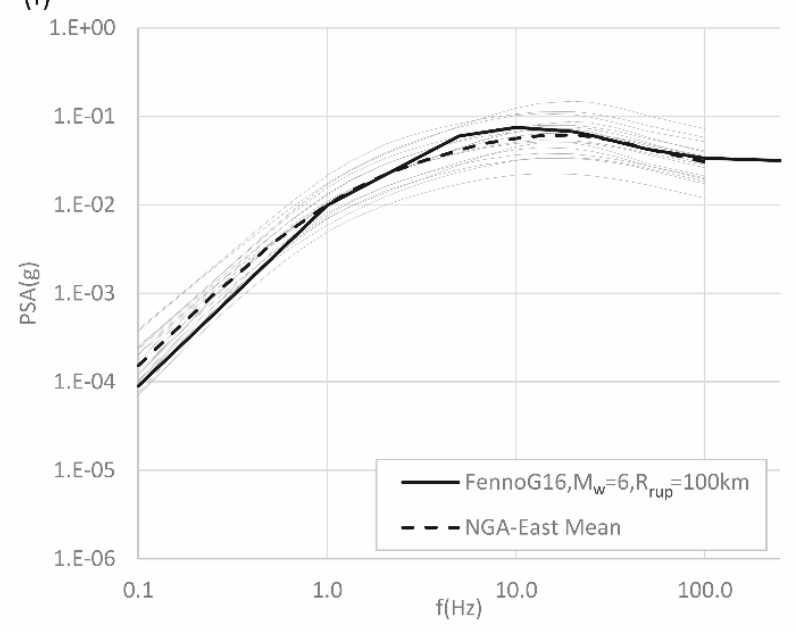


Figure 13. Comparison of Fenno-G16 GMPE with the suite of NGA-East GMPEs (gray lines) over ranges in which they apply and are of interest for probabilistic seismic hazard analysis (PSHA) in Finland; moment magnitude $\left(M_{\mathrm{w}}\right)(\mathrm{a}, \mathrm{b}) 4$, $(\mathrm{c}, \mathrm{d})$ 5 , and $(\mathrm{e}, \mathrm{f}) 6$, and rupture distances $\left(R_{\text {rup }}\right)=50$ and $100 \mathrm{~km}$. 